San Jose State University

SJSU ScholarWorks

Master's Theses

Master's Theses and Graduate Research

Fall 2015

\title{
Trajectories of Air Parcel Motions in Mars' Atmosphere Computed Using HYSPLIT
}

David Bruggeman

San Jose State University

Follow this and additional works at: https://scholarworks.sjsu.edu/etd_theses

\section{Recommended Citation}

Bruggeman, David, "Trajectories of Air Parcel Motions in Mars' Atmosphere Computed Using HYSPLIT" (2015). Master's Theses. 4625.

DOI: https://doi.org/10.31979/etd.9kn2-vwb2

https://scholarworks.sjsu.edu/etd_theses/4625

This Thesis is brought to you for free and open access by the Master's Theses and Graduate Research at SJSU ScholarWorks. It has been accepted for inclusion in Master's Theses by an authorized administrator of SJSU ScholarWorks. For more information, please contact scholarworks@sjsu.edu. 


\title{
TRAJECTORIES OF AIR PARCEL MOTIONS IN MARS' ATMOSPHERE COMPUTED USING HYSPLIT
}

\author{
A Thesis \\ Presented to \\ The Faculty of the Department of Meteorology and Climate Science \\ San José State University
}

In Partial Fulfillment

of the Requirements for the Degree

Master of Science

by

David Bruggeman

December 2015 
(C) 2015

David Bruggeman

ALL RIGHTS RESERVED 
The Designated Thesis Committee Approves the Thesis Titled

TRAJECTORIES OF AIR PARCEL MOTIONS IN MARS' ATMOSPHERE COMPUTED USING HYSPLIT

\author{
by \\ David Bruggeman \\ APPROVED FOR THE DEPARTMENT OF METEOROLOGY AND CLIMATE \\ SCIENCE
}

SAN JOSÉ STATE UNIVERSITY

December 2015

Dr. Alison F. C. Bridger

Department of Meteorology and Climate Science

Dr. Martin Leach

Department of Meteorology and Climate Science

Dr. Melina A. Kahre

NASA Ames Research Center 


\title{
ABSTRACT \\ TRAJECTORIES OF AIR PARCEL MOTIONS IN MARS' ATMOSPHERE COMPUTED USING HYSPLIT
}

\author{
by David Bruggeman
}

An analysis of the advection of air parcels in the Martian atmosphere during the 2001 global dust storm through the use of three-dimensional trajectories is presented. The Hybrid Single Particle Lagrangian Integrated Trajectory (HYSPLIT) model, wellknown for trajectory, dispersion, and deposition modeling, and originally developed for Earth was modified for Mars to provide forward and backward trajectories. The custom HYSPLIT for Mars uses meteorological input generated by the NASA Ames Mars General Circulation Model (MGCM). The 2001 global dust storm was the earliest on record $\left(\mathrm{L}_{\mathrm{s}} \sim 180^{\circ}\right)$ and originated from local dust storms around the Hellas basin as the storm expanded asymmetrically to the east. Trajectories near Hellas and Claritas Fossae correspond with dust transport detected using satellite imagery. Forward trajectories at $\mathrm{L}_{\mathrm{s}}$ $=184^{\circ}$ from Hellas show flow to the south, transporting dust around the south polar cap, while after $\mathrm{L}_{\mathrm{s}}=188^{\circ}$ there is an eastward shift in propagation. Air parcel trajectories intersecting the surface during the dust storm may indicate the processes involved with global dust storms contributing to dust layers in the polar regions. Backward trajectories from Claritas Fossae reveal the dust activity in this region was the result of local dust storm activity instead of the propagation of dust eastward from the Hellas region. 


\section{ACKNOWLEDGEMENTS}

We thank Dr. Roland Draxler of ARL and Dr. Jim Murphy for their valuable help with HYSPLIT and the MGCM. Thank you to Dr. Housiadas and Dimitris Mitrakos of the Greek Atomic Energy Commission for their assistance in understanding a way to modify the conversion program. An extra special thank you to Dr. Bridger for her patience in the everlasting struggle with HYSPLIT. 


\section{TABLE OF CONTENTS}

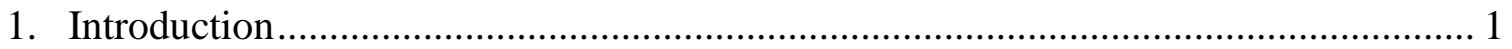

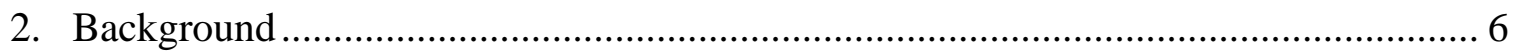

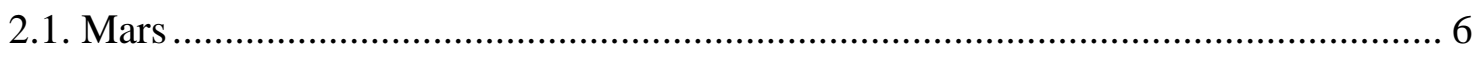

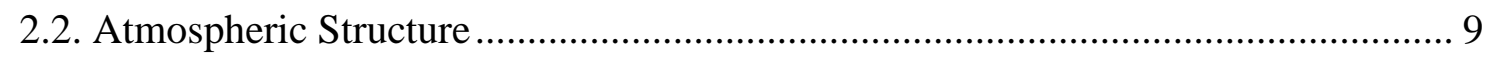

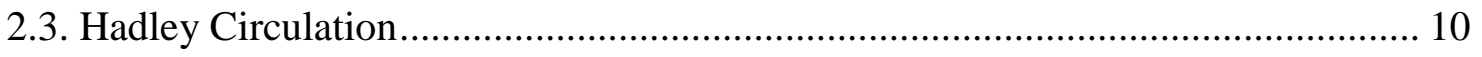

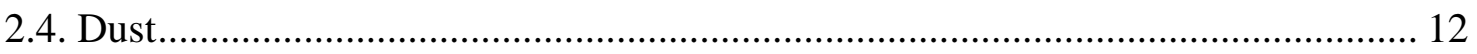

2.5. Dust Lifting Mechanisms ................................................................................. 14

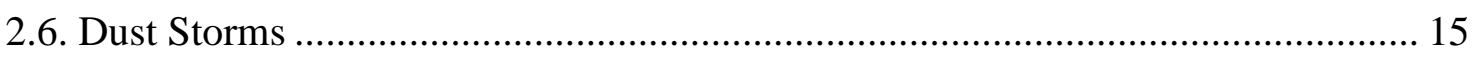

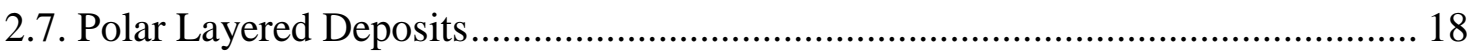

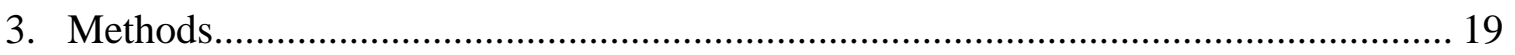

3.1. Overview of HYSPLIT ................................................................................ 19

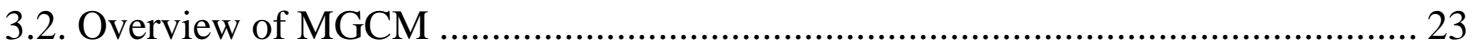

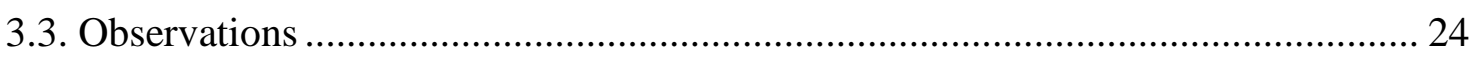

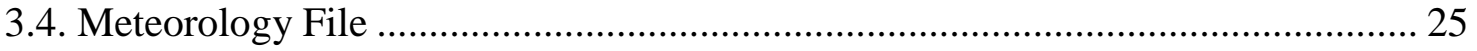

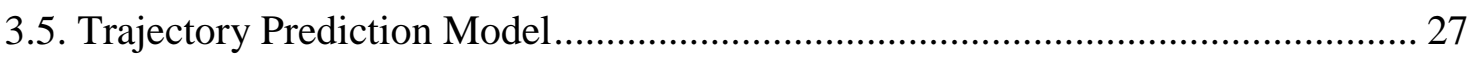

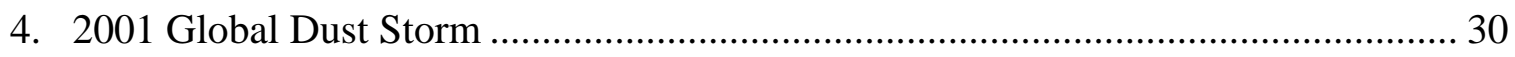

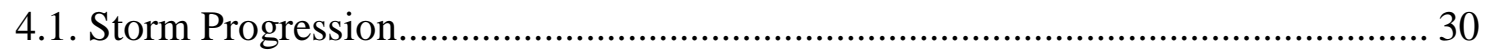

4.2. Claritas Storm Activity .................................................................................. 34

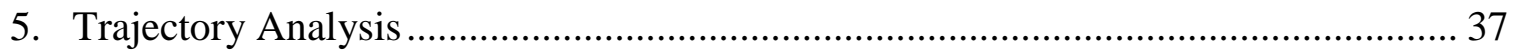




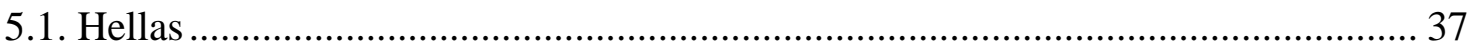

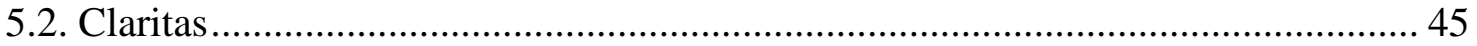

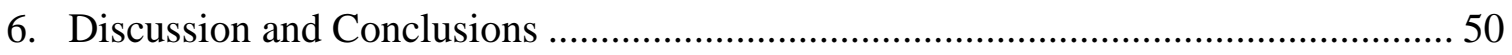

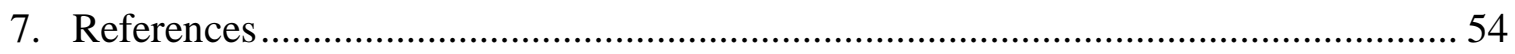

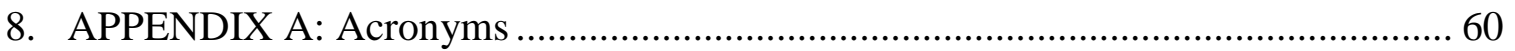

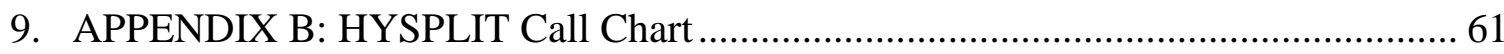




\section{LIST OF FIGURES}

FIGURE 1: Topographic map of Mars ..................................................................... 4

FIGURE 2: Martian orbital position and seasons ................................................. 9

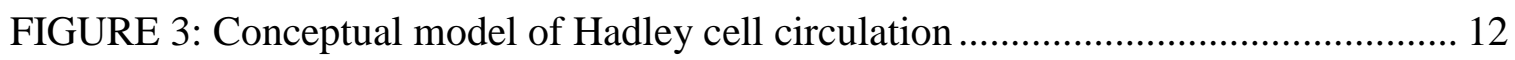

FIGURE 4: Example trajectories from Fukushima Daiichi accident ........................... 21

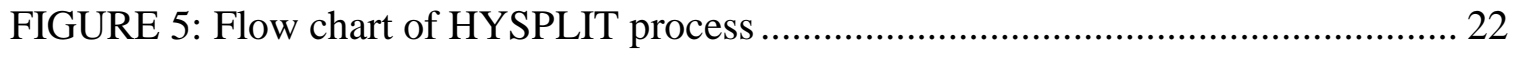

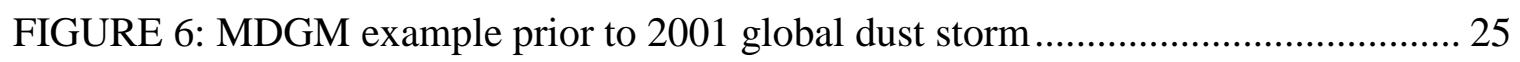

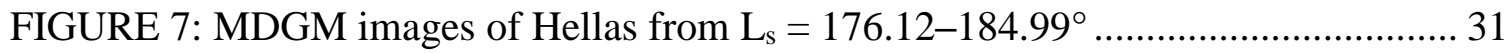

FIGURE 8: MDGM images of south polar cap from $\mathrm{L}_{\mathrm{s}}=185.5-191.22^{\circ} \ldots \ldots \ldots \ldots \ldots \ldots \ldots . . . . . . . . . .33$

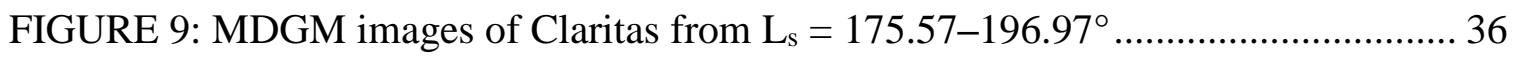

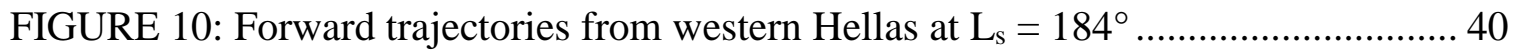

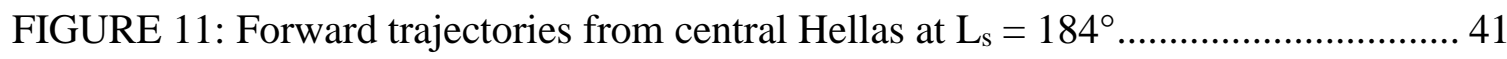

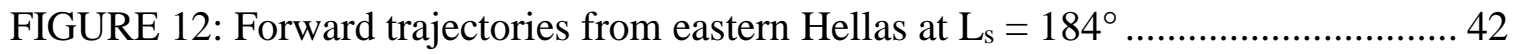

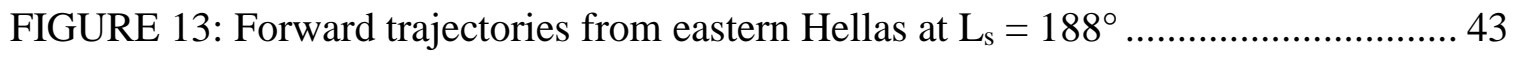

FIGURE 14: Backward trajectories around south polar cap ................................... 44

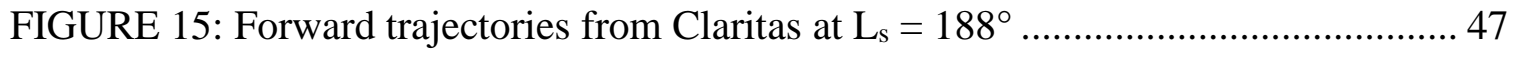

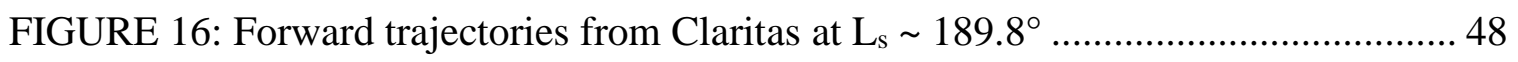

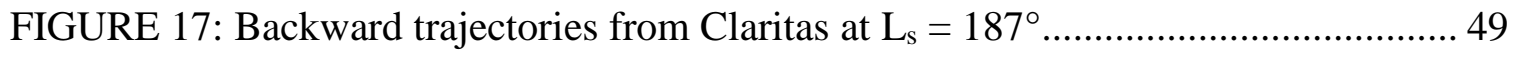




\section{LIST OF TABLES}

TABLE 1: Planetary and atmospheric parameters for Earth and Mars ............................ 7

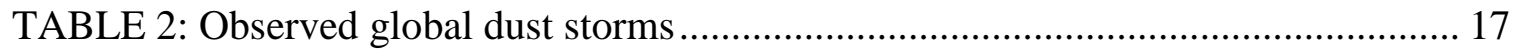




\section{Introduction}

The determination to learn more about other planets has grown extensively with the study of our neighbor planet Mars. While the primary focus has been on the past or future existence of life on Mars, it is not the sole purpose of studying the red planet. The Mars Atmosphere and Volatile Evolution satellite launched on 18 November 2013 and reached orbit on 21 September 2014. The satellite collects data on the Martian upper atmosphere and its interaction with the solar wind. The data allow us to study the history of the atmosphere and climate (Jakosky et al. 2015). The recognition of another planet's environment and climate can help in understanding the complex physics and chemistry occurring on Earth.

Mars is known for its barren surface and dusty atmosphere. The Martian dust cycle is a key component of the state of the climate system. For example, dust can change the albedo of the surface, and interact with the visible and infrared radiation to alter heating rates in the atmosphere. The dust cloud sizes range from local to global scales as dust is lifted from the surface and transferred throughout the atmosphere. Planet-encircling dust storms vary significantly in intensity, when they occur, and in duration. Dust storms typically occur around the southern hemisphere summer during the maximum insolation and can distribute dust between both hemispheres as dust can be lofted several tens of kilometers deep in the atmosphere (Read and Lewis 2004).

An objective of our study is to understand how significant plumes of dust shown by satellite imagery are transported. This is accomplished by constructing trajectories to follow dust that is advected around the Martian atmosphere during large dust storms 
using winds generated from a Mars general circulation model (MGCM). A terrestrial trajectory prediction model, the Hybrid Single Particle Lagrangian Integrated Trajectory (HYSPLIT), is used for transport and dispersion modeling based on winds from various models. HYSPLIT has been modified to allow the input of meteorological data from the MGCM, a unique application that has not been done prior to this study.

An application of the HYSPLIT presented in this study is to analyze the processes involved in dust transport for specific regions on Mars during the 2001 global dust storm. Previous studies observed the initiation and evolution of a global dust storm that occurred from June to November 2001 using images captured by the Mars Orbiter Camera (MOC) onboard the Mars Global Surveyor (MGS) satellite. The importance of this global dust storm is a result of its unusually early occurrence and vast amount of data collected due to Mars' favorable orbital position (Strausberg et al. 2005; Cantor 2007). The detailed observations available from the MGS-MOC are supplemented by the National Aeronautics and Space Administration (NASA) Ames MGCM to help analyze the source of the dust storm and the associated atmospheric transport response. Areas of interest include the Hellas basin impact crater, the source of the global dust storm, and a regional dust storm in Claritas Fossae that helped sustain high atmospheric dust levels until the dust filled both hemispheres. Another area includes the south polar cap where alternating layers of ice and dust known as polar layered deposits (PLDs) have been observed. The use of backward trajectories from our custom HYSPLIT helps in analyzing how the dust can settle on the polar surface.

The exploration of Mars began in 1964 where the NASA Mariner 4 captured the 
first images and temperature of the surface. The USSR successfully landed the Mars 2 spacecraft on the Martian surface in 1969, but the spacecraft failed before it could return data to Earth. The Viking mission in the summer of 1976 became the first to land on another planet and return images. The two Viking landers (VLs) touched down on the northern hemisphere of Mars equipped with 14 instruments designed to analyze the environment (Read and Lewis 2004). VL-1 landed in western Chryse Planitia and VL-2 in Utopia Planitia (Figure 1). Although the primary objective of the Viking mission was to identify evidence of living organisms, the VLs were equipped with pressure, temperature, and wind sensors (Hess et al. 1977). The expected lifespan of the VLs was 90 days; however, VL-1 continued until August 1980 and VL-2 until July 1978. The meteorology data captured by the VL spacecraft remain invaluable for studies of the Martian atmosphere (Kieffer et al. 1992; Read and Lewis 2004). 


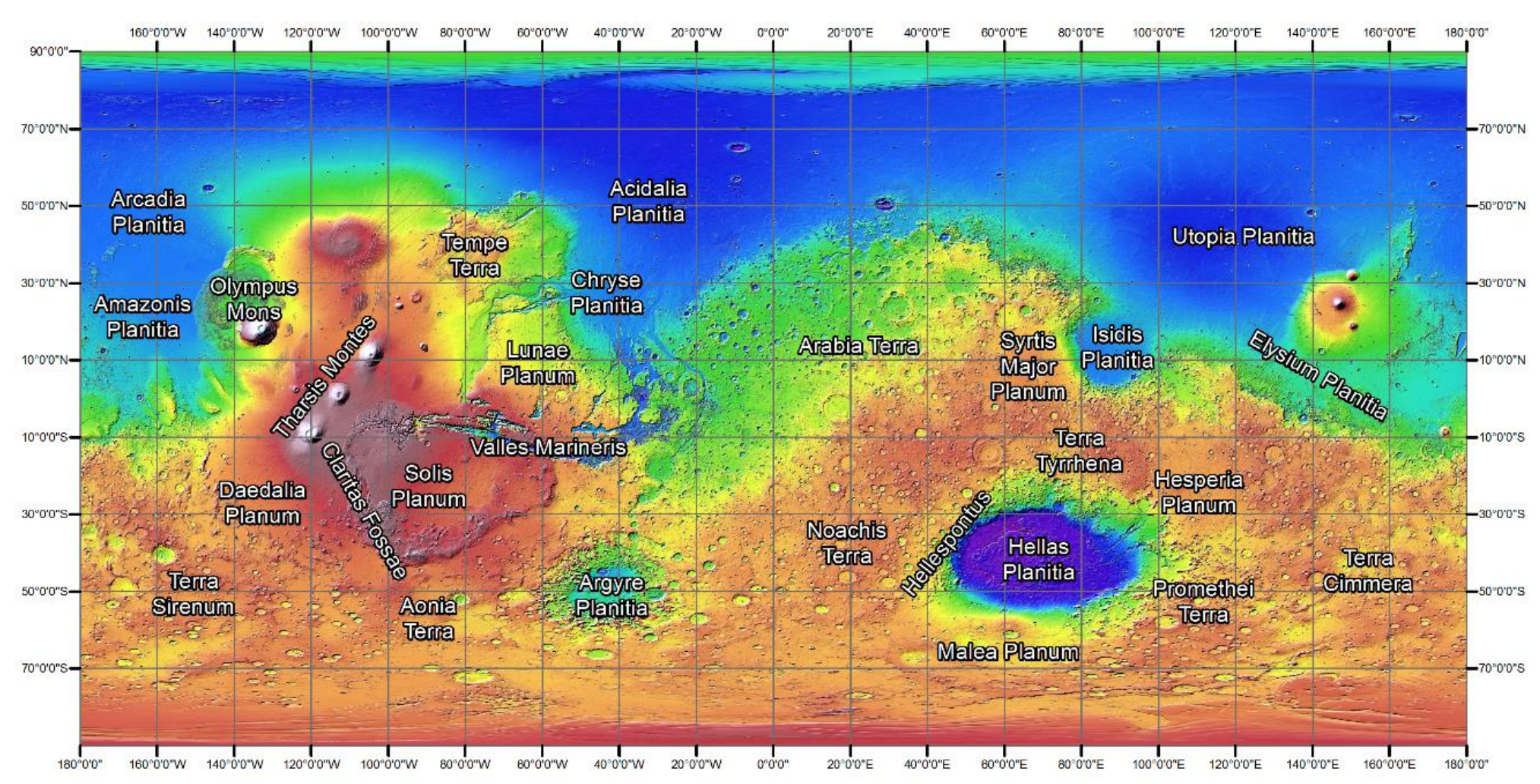

Topography (meters)

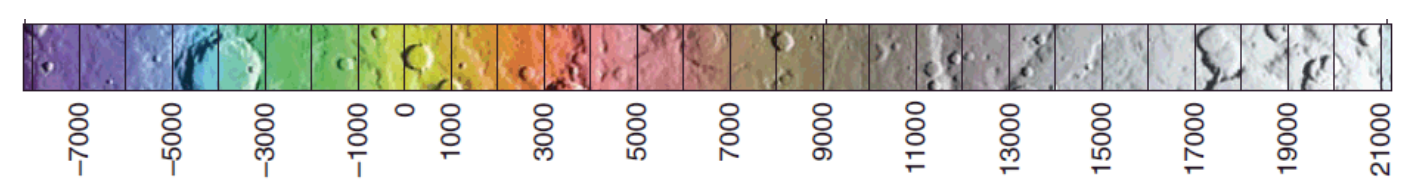

Figure 1. MGS-Mars Orbiter Laser Altimeter (MOLA) topographic map of Mars (map courtesy of the United States Geological Survey). 
The Mars Pathfinder (MPF), launched by NASA in December 1996 and landed southeast of VL-1 on 4 July 1997, attempted to demonstrate new lander technology for future missions. After arrival, MPF served as a scientific mission. MPF obtained an insitu atmospheric vertical profile through its entry, and measured surface meteorology during the nearly 90 days of operation. The images of Mars captured by the VL and MPF spacecraft revealed a rocky landscape and dusty atmosphere (Magalhães et al. 1999; Read and Lewis 2004).

A recent spacecraft to orbit Mars and observe atmospheric dust was the MGS with onboard instruments such as the MOC, Thermal Emission Spectrometer (TES), and Mars Orbiter Laser Altimeter (MOLA). The MGS began an elliptical orbit around Mars in September 1997 but transitioned to a nearly circular orbit and to a mapping phase by March 1999. The MGS was in a polar orbit 12 times per Martian day (sol), collecting data from $300 \mathrm{~km}$ above the surface (Wang and Ingersoll 2002; Read and Lewis 2004). The MGS-MOC contained a high resolution narrow-angle camera and two low resolution wide-angle cameras, which were always pointed at the spacecraft's nadir to provide daily global surface maps (Cantor et al. 2001). MGS-TES data provide information across the infrared spectra $(\sim 7-50 \mu \mathrm{m})$ to determine atmospheric temperature and opacity (Smith et al. 2002). The MGS-MOLA collected altimetry data to accurately measure the topography of the planet (Smith et al. 2001). The spacecraft was expected to stop sending data approximately in April 2003, but continued until November 2006 when the signal went silent (Wang and Ingersoll 2002; Montabone et al. 2015).

The latest rover sent to Mars is the NASA Mars Science Laboratory (MSL) 
mission that launched in November 2013 and landed the Curiosity rover in Gale Crater in August 2012. The radioisotope power system of Curiosity allows for the long-range mobility $(\sim 5-20 \mathrm{~km})$ of the rover for at least one Martian year (MY). The goal of the mission is to determine the past habitability of the planet (Vasavada et al. 2014).

\section{Background}

\subsection{Mars}

Mars was formed $\sim 4.5 \times 10^{9}$ years ago with a counterclockwise orbital and rotational motion, similar to most of the solar system. Several ancient civilizations revered Mars and named this red planet appearing in the night sky after a god of war or death (Read and Lewis 2004). Many planetary features of Mars are similar to Earth, while atmospheric properties vary greatly (Table 1). A Martian day lasts only 39 minutes longer than Earth and the axis tilt of both planets is near $24^{\circ}$. Compared with Earth, Mars is half the size, is $50 \%$ farther from the Sun, has a larger orbital eccentricity, has onethird of the surface gravity, and has a thin atmosphere (1\% of Earth) primarily consisting of carbon dioxide $\left(\mathrm{CO}_{2}\right)$. Mars' distinct eccentricity causes $44 \%$ more insolation at the planet's closest position to the Sun at perihelion compared with aphelion. Other than Mercury, Mars has the largest eccentricity of the planets in our solar system (Kieffer et al. 1992; Read and Lewis 2004). 
Table 1: Planetary and atmospheric parameters for Earth and Mars (Keifer et al. 1992;

Leovy 2001; Read and Lewis 2004)

\begin{tabular}{lcc}
\hline \multicolumn{1}{c}{ Parameter } & Earth & Mars \\
\hline Equatorial radius $(\mathrm{km})$ & 6371 & 3396 \\
Mass $(\mathrm{kg})$ & $5.98 \times 10^{24}$ & $6.46 \times 10^{23}$ \\
Distance from Sun $(\mathrm{AU})$ & $0.98-1.02$ & $1.38-1.67$ \\
Orbital eccentricity & 0.017 & 0.093 \\
Planetary obliquity $\left(^{\circ}\right)$ & 23.93 & 25.19 \\
Rotation rate $\Omega\left(10^{-5} \mathrm{~s}^{-1}\right)$ & 7.294 & 7.088 \\
Solar day $(\mathrm{s})$ & 86400 & 88775 \\
Year length $($ Earth days $)$ & 36524 & 68698 \\
Surface pressure $(\mathrm{hPa})$ & 1013 & $6-10$ \\
Surface gravity $\left(\mathrm{m} \mathrm{s}^{-2}\right)$ & 9.81 & 3.72 \\
Surface temperature $(\mathrm{K})$ & $230-315$ & $140-300$ \\
Dry gas constant $\left(\mathrm{J} \mathrm{kg}^{-1} \mathrm{~K}^{-1}\right)$ & 287 & 192 \\
Mean solar constant $\left(\mathrm{W} \mathrm{m} \mathrm{m}^{-2}\right)$ & 1367 & 589 \\
Dry adiabatic lapse rate $\left(\mathrm{K} \mathrm{km}^{-1}\right)$ & 9.8 & 4.5 \\
Scale height, $H_{p}=R \cdot T_{e} g^{-1}\left(\mathrm{~km}^{\prime}\right)$ & 7.5 & 10.8 \\
Atmospheric components & $\mathrm{N}_{2}(77)$ & $\mathrm{CO}_{2}(95)$ \\
(molar ratio - $\%)$ & $\mathrm{O}_{2}(21)$ & $\mathrm{N}_{2} \mathrm{O}(2.7)$ \\
& $\mathrm{Ar}(0.9)$ & $\mathrm{Ar}(1.6)$ \\
& $\mathrm{H}_{2} \mathrm{O}(0-4)$ & $\mathrm{O}_{2}(0.13)$ \\
\hline
\end{tabular}

Key regions and the Martian topography are depicted in Figure 1 based on images from the United States Geological Survey planetary database derived from the MGSMOLA. For Earth, the height above sea level is a reference to determine topography. The height above sea level cannot be defined for Mars' surface due to the absence of an ocean. To calculate the topography, the MGS-MOLA measures the planetary radius through laser pulses and subtracts that from the areoid radius at a given latitude and longitude. The global grid resolution is $1 \mathrm{~km} \times 2 \mathrm{~km}$ at the equator or $1 / 64^{\circ}$ latitude and $1 / 32^{\circ}$ longitude (Smith et al. 2001). The zero elevation datum corresponds to a mean atmospheric surface pressure of 6.1-hPa (Zuber et al. 1992). For Mars, the $0^{\circ}$ meridian is 
defined as the longitude of the Airy-o crater that astronomers in 1830-32 used to calculate the rotational period of the planet (Kieffer et al. 1992).

The northern hemisphere is predominantly smooth lowlands, and the southern hemisphere is primarily rough highlands with an average height of $3 \mathrm{~km}$ higher than the northern hemisphere. There is a low density of impact craters in the northern hemisphere and high density of impact craters in the southern hemisphere (Kieffer et al. 1992; Read and Lewis 2004). However, the Hellas Basin impact crater in the southern hemisphere is the lowest elevation on Mars, at $8.18 \mathrm{~km}$ below zero elevation and a diameter of 2200 $\mathrm{km}$. An impact of this magnitude would have drastically changed the climate. The tallest feature on Mars is the Olympus Mons volcano with an elevation of $25 \mathrm{~km}$ and diameter of $624 \mathrm{~km}($ Read and Lewis 2004).

The solar longitude $\left(\mathrm{L}_{\mathrm{s}}\right)$ or areocentric longitude of Mars is the orbital angle of Mars relative to the Sun throughout the year (Figure 2). A MY begins during the northern hemisphere spring equinox $\left(\mathrm{L}_{s}=0^{\circ}\right)$, continues to summer solstice at $\mathrm{L}_{s}=90^{\circ}$, to the autumnal equinox at $\mathrm{L}_{\mathrm{s}}=180^{\circ}$, and to the winter solstice at $\mathrm{L}_{\mathrm{s}}=270^{\circ}$. Aphelion occurs prior to the northern summer solstice near $\mathrm{L}_{\mathrm{s}}=71^{\circ}$ and perihelion occurs prior to the northern winter solstice near $\mathrm{L}_{\mathrm{s}}=251^{\circ}$. A Martian year consists of 668.6 sols; thus, $\mathrm{a}$ sol is equivalent to $\sim 0.6^{\circ}$ of $\mathrm{L}_{\mathrm{s}}$ on average. Clancy et al. (2000) proposed a calendar with MY 1 at 08:31 UTC 11 April 1955, corresponding to the spring equinox that occurred prior to the global dust storm of 1956. 


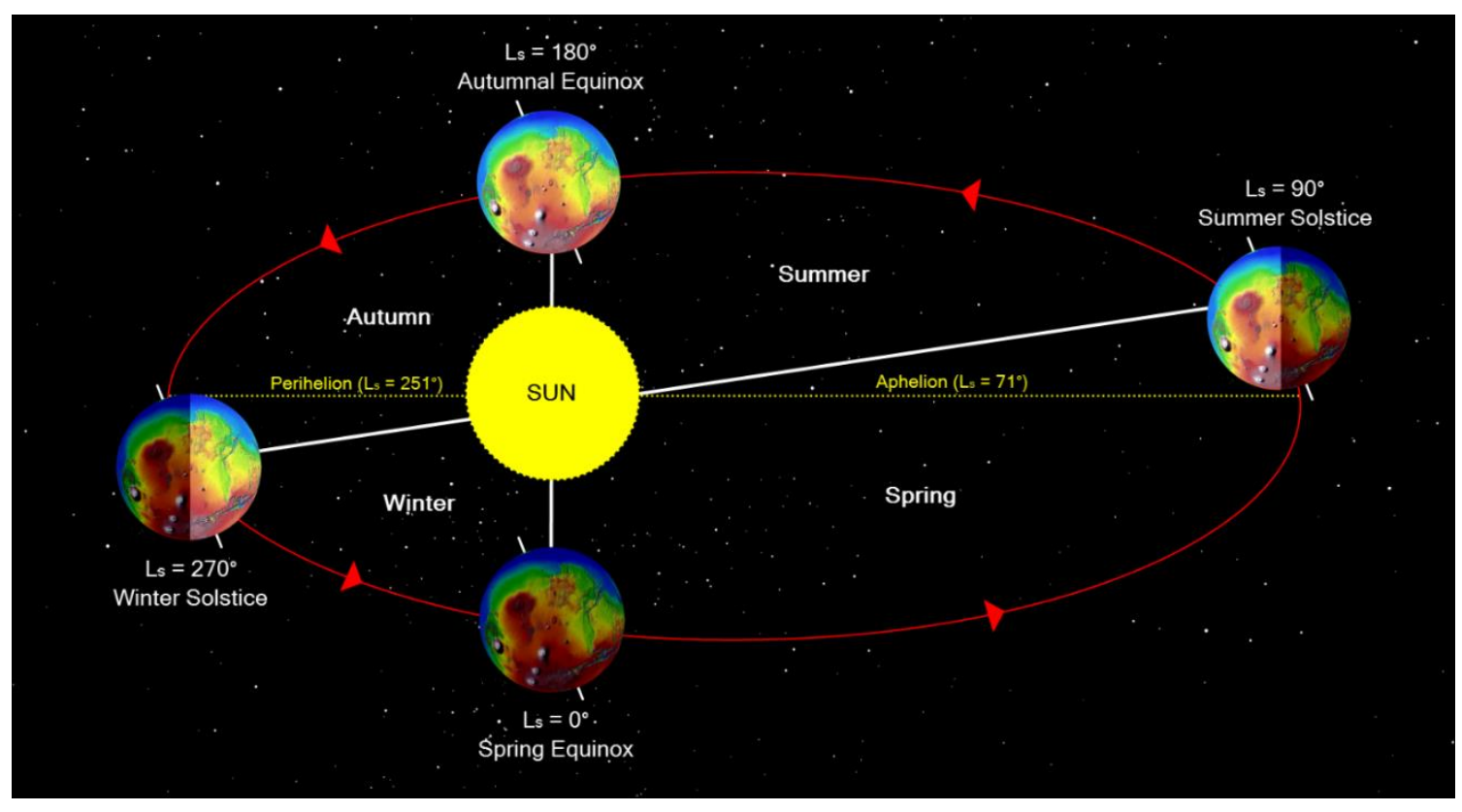

Figure 2. Martian orbital position and seasons in relation to the Mars-Sun angle.

\subsection{Atmospheric Structure}

The thin atmosphere of Mars, dominated by $\mathrm{CO}_{2}$, influences a different atmospheric structure compared with Earth. Early in-situ measurements of the Martian atmosphere were acquired by the VL and MPF spacecraft through the entry, descent, and landing phase. The VLs arrived in early northern hemisphere summer, and MPF arrived during the late northern hemisphere summer. The measurements of density, pressure, and temperature of the MPF during similar seasons and nearby location to VL-1 allowed the opportunity to search for atmospheric changes since the Viking mission. The measurements during descent ranged from $160 \mathrm{~km}$ to near the surface, and results revealed the atmosphere on Mars is divided into broad sections: lower, middle, and upper atmosphere (Schofield et al. 1997; Magalhães et al. 1999). 
The lower atmosphere of Mars is comparable to Earth's stratosphere in regards to surface pressure and temperature. The surface pressure of Mars ranges from 6-10 hPa and surface temperatures range from $140-300 \mathrm{~K}$. The variation in surface pressure is the result of the seasonal variability in $\mathrm{CO}_{2}$ (Leovy 2001; Read and Lewis 2004). Processes involved in heating the lower atmosphere include the major contributor of the absorption of sunlight by atmospheric dust and a minor greenhouse effect from $\mathrm{CO}_{2}$ inhibiting infrared radiation escaping to space. Mars' thin atmosphere prevents the retention of daytime heat, creating large temperature fluctuations from day to night (Read and Lewis 2004).

The seasonal and interannual variation in the vertical distribution of dust can cause an indistinguishable boundary between the lower and middle atmospheres. This boundary has an average height of $\sim 45 \mathrm{~km}$ above ground level (AGL) at a pressure $\sim 0.1$ $\mathrm{hPa}$. The middle atmosphere extends to $\sim 100 \mathrm{~km}$ with cold temperatures decreasing with increasing height. The upper atmosphere extends above $110 \mathrm{~km}$ and has an increasing temperature profile above $120 \mathrm{~km}$ where the VL and MPF spacecraft measured a thermosphere (Schofield et al. 1997; Magalhães et al. 1999; Barlow 2008).

\subsection{Hadley Circulation}

Previous studies showed a Hadley cell in each hemisphere around equinox $\left(\mathrm{L}_{\mathrm{s}}=\right.$ $180^{\circ}$ ), similar to Earth, and the development of a single cross-equatorial cell between $30^{\circ} \mathrm{N}$ and $30^{\circ} \mathrm{S}$ during the solstices (Haberle et al. 1993). Recent studies with MGCMs have revealed an asymmetry in the Hadley circulation below $20 \mathrm{~km}$ in the annual average and equinoxes (Takahashi et al. 2003; Zalucha et al. 2010). The asymmetry corresponds 
to the northern hemisphere cell intensity exceeding the southern hemisphere cell with the ascending branch of the Hadley cell extending into the southern hemisphere (Figure 3a). Thus, air parcels are lifted by the Hadley circulation in the southern hemisphere and advected north into the northern hemisphere where they descend into the subtropics. Above $20 \mathrm{~km}$, the MGCM simulations show a symmetric circulation with respect to the equator (Takahashi et al. 2003; Zalucha et al. 2010).

The variation in Mars' orbit relative to the Sun has been shown not to cause the asymmetrical Hadley cell circulation (Takahashi et al. 2003). At equinox, insolation is symmetric with respect to the equator, heating the surface of each hemisphere evenly and causing rising air at the equator. However, Smith et al. (2001) observed maximum temperatures near $10-20^{\circ} \mathrm{S}$ in the lower atmosphere as a result of the topographic dichotomy of Mars. In addition, some regions topographic relief exceeds the scale height of the atmosphere $(\sim 10.8 \mathrm{~km})$, so the topography can greatly affect the atmospheric circulation. Studies with MGCMs have concluded that the elevation difference in topography can cause the asymmetrical Hadley circulation. The asymmetry in circulation, even at equinoxes, significantly impacts the transport of dust between the northern and southern hemispheres (Richardson and Wilson 2002; Read and Lewis 2004; Zalucha et al. 2010).

A conceptual model for the cross-equatorial cell during the northern hemisphere winter solstice is shown in Figure 3b. The circulation direction between the northern hemisphere summer solstice and winter solstice are opposite. Convective activity becomes stronger during the southern hemisphere summer as a result of Mars' large 
eccentricity. This subsequently causes a stronger cross-equatorial flow compared to the northern hemisphere summer (Haberle et al. 1993; Richardson and Wilson 2002; Zalucha et al. 2010).
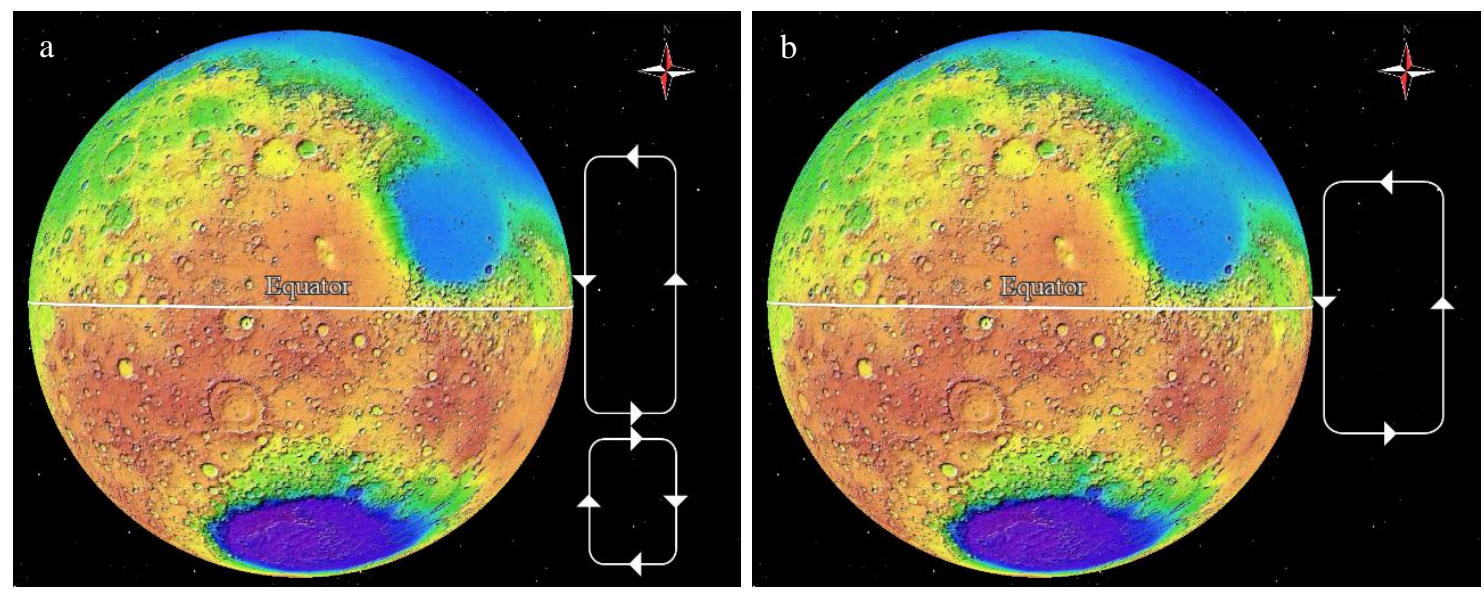

Figure 3. Conceptual model of Hadley cell circulation (a) below $20 \mathrm{~km}$ during equinoxes and (b) northern hemisphere winter solstice.

\subsection{Dust}

An enigma for early scientists studying the Martian atmosphere was the observation that the sky is pink or butterscotch compared with our blue sky. The main contributor to this color is the continuous suspension of fine-grained red dust. The dust particle sizes are typically larger than air molecules and the wavelength of visible light. MPF revealed that dust must exist high in the atmosphere due to the illumination of the atmosphere up to two hours after sunset (Read and Lewis 2004). In 1971, the Mariner 9 spacecraft observed the vertical extent of dust to reach $65-70 \mathrm{~km}$ during a global dust storm (Anderson and Leovy 1978). Cameras onboard polar orbiting satellites such as the 
MGS-MOC and the Mars Climate Sounder (MCS) onboard the currently orbiting satellite Mars Reconnaissance Orbiter (MRO), have also observed this high altitude dust (Read and Lewis 2004).

Suspended dust provides mid-level atmospheric heating through the absorption of insolation and infrared radiation. As the suspended dust absorbs insolation, radiation is prevented from reaching the surface causing cooling near the ground. At night, dust layers prevent heat from escaping and cause warmer surface temperatures (Read and Lewis 2004; Barlow 2008).

The column optical depth or optical thickness $(\tau)$ is a measure of the fractional depletion of radiation traveling through an atmospheric column due to absorption and scattering by dust. During relatively clear days, observations show values of $\tau$ in the range of $0.3-0.5$, indicative of a constant background haze of dust. Models show that this haze can cause global mid-level atmospheric warming at least 5-10 K compared with a relatively clear atmosphere (Basu et al. 2004). Dust loading increases during southern hemisphere spring and summer as $\tau$ increases to $2-5$ and dust loading decreases during northern hemisphere spring and summer (Read and Lewis 2004).

Montabone et al. (2015) developed the climatology of dust optical depth from MY 24-31 using measurements from various missions and instruments (e.g., MGS-TES, MRO-MCS). Results during non-global dust storm years revealed an increase in dust around $\mathrm{L}_{\mathrm{s}}=150^{\circ}$ in the southern hemisphere, and a peak between $\mathrm{L}_{\mathrm{s}}=210^{\circ}$ and $240^{\circ}$. From $L_{s}=250-300^{\circ}$, strong dust lifting occurs in the southern polar region. A pause in large dust storms for other latitudes occurs after $\mathrm{L}_{\mathrm{s}} \sim 260^{\circ}$ as the result of a weakening in 
low-altitude northern baroclinic waves called the "solstical pause." After $\mathrm{L}_{\mathrm{s}} \sim 310^{\circ}$, the solstical pause ends and a late peak in optical depth occurs (Montabone et al. 2015).

\subsection{Dust Lifting Mechanisms}

The background haze of dust in the Martian atmosphere is not likely due to slow dust settlement from global dust storms. Studies show that wind stress and dust devils contribute to the dust lifting that causes background haze (Basu et al. 2004; Kahre et al. 2006). Kahre et al. (2006) used the MGCM to conclude dust devil lifting contributes to the background haze during northern hemisphere spring and summer while the annual opacity maximum during the southern hemisphere spring and summer is the result of wind stress. Wind stress refers to the lifting of particles as a result of the surface winds. Sand particles $\geq 20 \mu \mathrm{m}$ in diameter removed from the surface due to strong low-level wind stress typically fall immediately to the surface. The process of saltation then takes place, where particles fall out of the atmosphere, and impact finer particles that become suspended in the atmosphere. Airborne dust particles typically range from $1-2.5 \mu \mathrm{m}$ in diameter (Basu et al. 2004; Read and Lewis 2004).

Dust devils are convective vortices of strong vertical motion and help maintain the background dust opacity levels. During the summer, thermally-driven convection during the day can develop a convective boundary layer up to $10 \mathrm{~km}$ deep. In areas of strong heating, the convection can develop a vortex of low pressure and a strong updraft leading to the formation of a dust devil (Read and Lewis 2004). Dust devils are prevalent during the southern hemisphere late spring to early fall, and occur more frequently around Amazonis Planitia (Kahre et al. 2006; Reiss et al. 2014). Dust devils cause dark 
streaks on the ground as they lift dust from the surface and reveal the dark ground below (Read and Lewis 2004).

The VL spacecraft first discovered dust devils on Mars and the VLs experienced the passage of a dust devil over their locations measuring winds greater than $25 \mathrm{~m} \mathrm{~s}^{-1}$ with gusts up to $44 \mathrm{~m} \mathrm{~s}^{-1}$ (Ryan and Lucich 1983). The MSL rover Curiosity measured numerous rapid pressure drops at Gale Crater ranging from 0.5-2.5 Pa, interpreted as dust devil passage (Kahanpää et al. 2014). Several studies analyzing dust devils using satellite observations from the MGS, Mars Express (Stanzel et al. 2008), and the MRO (Choi and Dundas 2011; Reiss et al. 2014) yielded similar results to dust devil wind speed and direction of motion climatology. Choi and Dundas (2011) calculated tangential speeds ranging from 20-30 $\mathrm{m} \mathrm{s}^{-1}$ and Reiss et al. (2014) found horizontal wind speeds from 4-25 $\mathrm{m} \mathrm{s}^{-1}$. The dust devils on Mars are larger in proportion to Earth and can reach several hundred meters across and have heights of up to $8 \mathrm{~km}$, evidenced through images from the MGS-MOC (Read and Lewis 2004). Stanzel et al. (2008) found an average height for dust devils of $660 \mathrm{~m}$ and average diameter of $230 \mathrm{~m}$.

\subsection{Dust Storms}

Dust storms have been observed on Mars in all seasons since the eighteenth century through the use of telescope and satellite observations (Read and Lewis 2004). Martian dust storms are categorized based on size and duration as defined by Cantor et al. (2001). A "local" dust storm has a spatial area limit of $1.6 \times 10^{6} \mathrm{~km}^{2}$ or lasts for $<3$ sols. Once a dust storm reaches an area $\geq 1.6 \times 10^{6} \mathrm{~km}^{2}$ and lasts $>3 \mathrm{sols}$, it is called a "regional" dust storm (Cantor et al. 2001). The dust storm season occurs around 
perihelion ranging from $L_{s} \sim 161-326^{\circ}$, where regional dust storms are more prevalent to occur (Martin and Zurek 1993). Local and regional dust storms that occur throughout the year can significantly elevate dust into the atmosphere. However, the background level of dust persists in the absence of dust storms (Read and Lewis 2004; Montabone et al. 2015).

A global or planet-encircling dust storm comprises local and regional storms that yields a sustainable dust cloud with a vertical extent of at least one scale height and shrouds one or both hemispheres (Cantor et al. 2001). Global dust storms spread dust over the planet with the convergence of two or more regional storms, and are the rarest dust storm events occurring every 2-4 MYs (Martin and Zurek 1993). These large dust storms have been observed primarily in the spring and summer of the southern hemisphere from $L_{s}=204-300^{\circ}$, which is the time of maximum insolation (Zurek and Martin 1993; Montabone et al. 2015). The exception to this time frame is the 2001 global dust storm that began at $\mathrm{L}_{\mathrm{s}} \sim 180^{\circ}$.

Table 2 shows the global dust storms observed in the past century. Before 2001, there were five confirmed planet-encircling storms observed in 1956, 1971/72, 1973, and two in 1977 (Zurek and Martin 1993). The storms listed before 1971 were detected by telescope observations. The primary locations observed to have initiated previous global dust storms are around Hellas, the plains near Claritas Fossae, and Isidis Planitia. The VLs provided visible optical depth and wind speed measurements during two global dust storms occurring in 1977. Their measurements showed during the first 1977 global dust storm (1977a), $\tau$ increased to $\sim 3$ after northern hemisphere autumnal equinox and quickly 
returned to normal levels prior to $L_{s}=270^{\circ}$. The $1977 \mathrm{~b}$ global dust storm was stronger as $\tau$ increased to $\sim 5$ and returned to normal levels at a much slower rate (Martin and Zurek 1993). During the onset of the 1977 global dust storms, the VLs measured relatively weak wind speeds with VL-1 measuring a maximum surface wind gust of $26 \mathrm{~m} \mathrm{~s}^{-1}$ and VL-2 measuring a maximum wind gust up to $14 \mathrm{~m} \mathrm{~s}^{-1}$ (Ryan and Henry 1979). The 2001 global dust storm in MY 25 occurred the earliest in the dust storm season during the northern hemisphere autumnal equinox. The latest global dust storm occurred in MY 28 and was captured by the Mars Color Imager onboard the MRO (Cantor et al. 2008). The origin of the MY 28 global dust storm is unclear, but a dust storm from Chryse moved south toward dust storms between Noachis and Hellas in the southern hemisphere (Wang and Richardson 2015). Regional dust activity in MY 28 near $\mathrm{L}_{\mathrm{s}}=220^{\circ}$ was weaker than previous years until near solstice at $\mathrm{L}_{\mathrm{s}}=260^{\circ}$ when dust storms intensified to create a global dust storm causing atmospheric heating ranging from 30-40 K (Smith 2009).

Table 2: Observed global dust storms (Zurek 1982; Read and Lewis 2004; Montabone et al. 2015)

\begin{tabular}{cccc}
\hline \hline Mars year & Earth year & Starting $\mathbf{L}_{\mathbf{s}}\left({ }^{\circ}\right)$ & Initial location \\
\hline-16 & 1924 & 310 & Unknown \\
1 & 1956 & 249 & Hellespontus \\
9 & $1971 / 72$ & 260 & Hellespontus \\
10 & 1973 & 300 & Solis, Claritas, Meridiani \\
12 & 1977 & 204 & Hellas and Argyre Planitia \\
12 & 1977 & 268 & Argyre? \\
15 & 1982 & 208 & Unknown \\
21 & 1994 & 201 & Unknown \\
25 & 2001 & 180 & Hellas Planitia \\
28 & 2007 & 260 & Southern hemisphere \\
\hline
\end{tabular}


The large quantities of dust lofted by global dust storms has been shown to affect Hadley cell circulations, atmospheric temperatures, and albedo (Haberle et al. 1993). MGCM studies have shown that an increase in dust loading at equinox causes a strengthening in the southern Hadley cell and subsequently shifts the rising branch northward (Zalucha 2014). Measurements of the 1977a global dust storm by VL-1 yielded a daytime surface temperature decrease of $19 \mathrm{~K}$ and nighttime increase of $\sim 15 \mathrm{~K}$ (Ryan and Henry 1979). The change in albedo caused by global dust storms could influence global surface temperatures as deposition of dust brightens the surface and dust removal darkens the surface. During the 2001 global dust storm, deposition in the southern hemisphere increased the albedo by $3.5 \%$, and dust removal in the northern hemisphere decreased the albedo by $2.5 \%$. The change in albedo potentially caused a decrease in global average surface temperatures by $1 \mathrm{~K}$ (Cantor 2007).

\subsection{Polar Layered Deposits}

The polar caps on Mars consist of both a permanent cap that persists all year and a seasonal $\mathrm{CO}_{2}$ cap that exists from fall through spring. A distinct difference between the polar caps is that the north residual cap consists of water ice, while the south residual cap is dominated by $\mathrm{CO}_{2}$ ice with traces of water ice. The north residual cap has a diameter of $1100 \mathrm{~km}$ and covers most of the area poleward of $80^{\circ} \mathrm{N}$. By contrast, the south residual cap extends to $400 \mathrm{~km}$ in diameter and is offset from the geographic pole with a center of $87^{\circ} \mathrm{S}, 315^{\circ} \mathrm{E}$ (Calvin and Martin 1994; Read and Lewis 2004; Giuranna et al. 2007).

The PLDs exist on the polar caps of Mars and consist of alternating layers of ice 
and dust that have been observed for decades (Murray et al. 1972; Read and Lewis 2004). The dust associated with these deposits has been lifted from the surface, transported through the atmosphere, and deposited in the polar areas. The PLDs stratigraphy are visible from satellite and are believed to be caused by variations in the Martian climate as a result of past significant changes in Mars' obliquity and eccentricity (Read and Lewis 2004; Hvidberg et al. 2012). An objective for this study is to understand the possible transportation of dust to the polar surface during a global dust storm. HYSPLIT can be used to produce backward trajectories starting from the polar surface in order to understand the source of dust that reaches the surface.

\section{Methods}

\subsection{Overview of HYSPLIT}

HYSPLIT was developed at the Air Resources Laboratory (ARL) in 1982 through a collaboration between the National Oceanic and Atmospheric Administration and Australia's Bureau of Meteorology. HYSPLIT computes air parcel trajectories, dispersion, and deposition calculations through a puff or particle approach (Draxler 1999). Initially, the model used only rawinsonde observations as input, but its capabilities have since expanded (Draxler and Taylor 1982).

HYSPLIT answers the question of how air parcels are transported through the atmosphere by the advection of winds generated by a wide variety of numerical models. The model utilizes a hybrid of the Lagrangian approach that moves the frame of reference with moving air parcels, and the Eulerian approach with a three-dimensional fixed frame of reference. HYSPLIT includes stability and dispersion equations and advection 
algorithms to simulate atmospheric transport of single or multiple air parcels. HYSPLIT version 4.9 has updated the advection algorithm to provide temporal interpolation. The model is used by a plethora of disciplines ranging from local emergency managers requesting dispersion forecasts, requests from air quality regulators, and international dispersion forecasts in case of a large scale nuclear incident (Draxler 1999).

A recent application of HYSPLIT analyzed the Fukushima Daiichi nuclear complex meltdown in 2011. Figure 4 shows an example of trajectories calculated by HYSPLIT from the Fukushima site starting at 12 March 2011 from 500 m AGL for a 120-hour duration. This example employs the ensemble option that starts multiple trajectories from the same point, but offsets the horizontal and vertical meteorological grid by one grid point in every direction resulting in 27 trajectories. Several studies used HYSPLIT to analyze the dispersion and transport of radionuclides from Fukushima (Draxler and Rolph 2012; Draxler et al. 2013; Eslinger et al. 2014). 


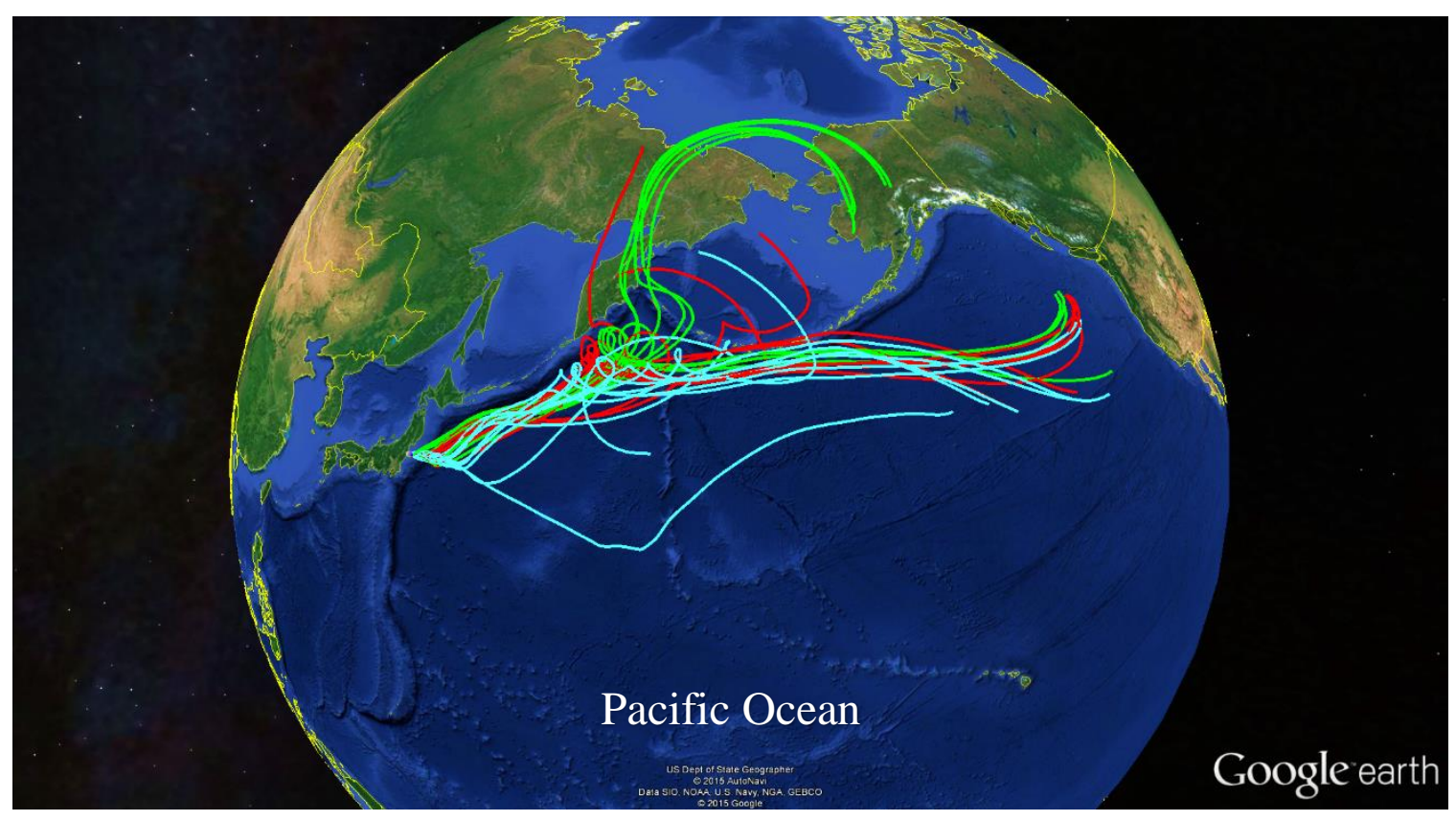

Figure 4. HYSPLIT example from Fukushima Daiichi on 12 March 2011 using a trajectory ensemble option with the same starting point at $500 \mathrm{~m}$ AGL and an offset meteorological grid for each of the 27 trajectories (Draxler and Rolph 2015; Rolph 2015).

HYSPLIT requires gridded meteorology data that can come from various meteorological models. In order to accept the model data, pre-processing is typically required using conversion programs that render the data in HYSPLIT's required format (ARL). The process is shown in Figure 5, which shows the flow as model data are read into the specific conversion program to translate the data to ARL format, external to HYSPLIT. The installation provides example conversion programs to read meteorological variables from a variety of models (e.g., NAM, WRF, ECMWF). A basic conversion program, dat2arl, converts model output data to ARL format. Dat2arl was adapted in our case to accept Mars meteorology data, and convert it to HYSPLIT format. 
After reformatting the data, HYSPLIT can read the converted meteorology data and then run the prediction. The output is the trajectory, dispersion, or deposition prediction that was requested by the user as a text file, graphic, or GIS file.

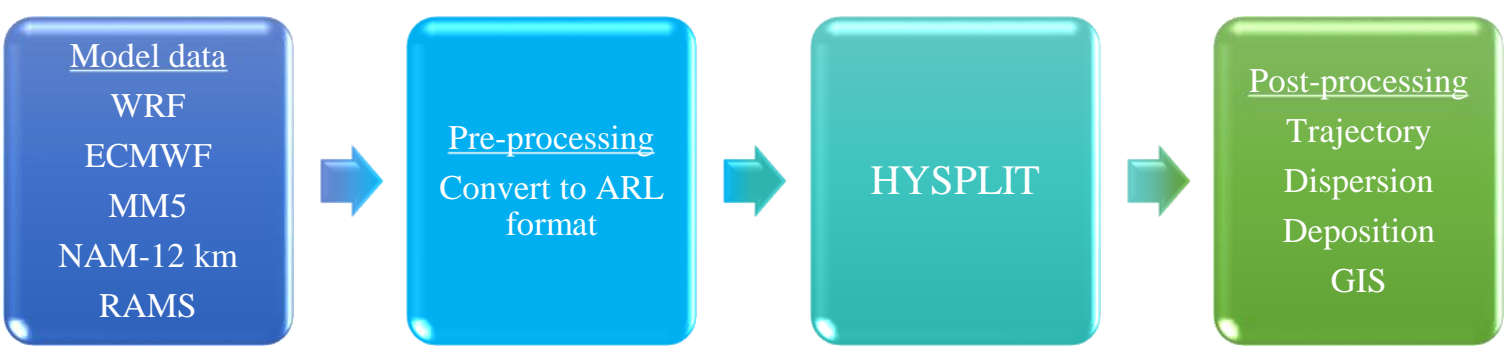

Figure: 5. Flow chart of HYSPLIT configuration for a sample of models.

HYSPLIT has predominantly been used for operational purposes in the past. Dreher (2009) configured HYSPLIT in order to provide an effective way for trajectories to be calculated operationally for the National Weather Service and Spaceflight Meteorology Group using NAM and RUC model data. Housiadas (1999) modified dat2arl to develop a custom version of HYSPLIT that opens several gridded forecast data sets from the Hellenic National Meteorological Service. The custom dat2arl developed by Housiadas (1999) aided in the modification of dat2arl used for our diagnostic study.

For the purpose of this study, only the trajectory prediction for a single particle is used to obtain the transport of an air parcel in the atmosphere. The air parcel trajectories assume a massless dust particle can flow through the atmosphere without experiencing sedimentation. The HYSPLIT functions not used in this study include the dispersion and deposition simulations and the puff approach. The deposition calculation of particles 
would allow the input of particle characteristics (e.g., size, density, shape).

The latest version of HYSPLIT is available at http://ready.arl.noaa.gov/index.php. An installation package of HYSPLIT is available for Windows PC, Mac OS, UNIX or LINUX (Draxler 1999). The UNIX version allowed the modification of HYSPLIT's source code for this study.

\subsection{Overview of $M G C M$}

General circulation models simulate the physical processes occurring in the atmosphere. The atmospheric general circulation of Mars has been successfully modeled through the interpretation of data obtained by spacecraft missions to Mars. Popular

models include MGCMs developed at NASA Ames Research Center (Leovy and Mintz 1969), the French Laboratoire de Météorologie Dynamique (Hourdin 1992), Oxford University (Collins and James 1995), and Princeton University (Wilson and Hamilton 1996).

The meteorology data used for this study come from the NASA Ames MGCM. The MGCM version 1.7.3 is a hydrostatic, finite difference model that simulates the Martian atmosphere numerically for a desired period using the Arakawa C-Grid. In this study, a grid spacing of $7.5^{\circ}$ latitude, $9^{\circ}$ longitude, and 16 vertical sigma levels is used. This coarse resolution is used to ensure the functionality of the model and HYSPLIT process, and requires less computing time. The model outputs primary meteorological variables such as wind, temperature, and pressure at specified time steps. Our scenario includes a modest dust loading $(\tau=0.3)$ when the atmosphere is relatively clear. The radiative heating rates from airborne $\mathrm{CO}_{2}$ and dust are calculated in the model. Water 
and $\mathrm{CO}_{2}$ ice cloud microphysics schemes are not included (Haberle et al. 1993; Kahre and Haberle 2010).

The physical modeling required for a general circulation model can be difficult for extraterrestrial planets due to the lack of observations. Other difficulties include a condensing atmosphere of $\mathrm{CO}_{2}$ to ice at the poles and a strong contrast of the boundary layer height; tens of meters at night and exceeding $10 \mathrm{~km}$ during the day. The Martian atmosphere can make the MGCM simpler due to its $\mathrm{CO}_{2}$-dominated atmosphere and lack of oceans. The absorption of infrared radiation occurs from only $\mathrm{CO}_{2}$ and the complex ocean-atmosphere coupling can be avoided (Read and Lewis 2004).

\subsection{Observations}

The MGS spacecraft was in orbit during the 2001 global dust storm in MY 25 and the MGS-MOC recorded many images of the planet before, during, and after the storm. Mars Daily Global Map (MDGM) images use daily MGS-MOC images to capture atmospheric phenomena (e.g., dust storms, water-ice clouds) ranging from MY 24-28. Each map is a composite of 13 consecutive pairs of daytime red and blue MGS-MOC global strips at $7.5 \mathrm{~km}_{\text {pixel }}{ }^{-1}$ or $3.75 \mathrm{~km}_{\text {pixel }}{ }^{-1}$ resolution. The MGS-MOC swaths in the red and blue wavelengths help identify clouds and dust. Most of the images taken during the global dust storm are presented in $3.75 \mathrm{~km} \mathrm{pixel}^{-1}$ resolution. Note the 13 swath pairs were acquired throughout a sol, thus the maps are asynoptic and do not represent a snapshot in time. The MDGM images presented here are projected as cylindrical equatorial maps from $60^{\circ} \mathrm{N}$ to $60^{\circ} \mathrm{S}$, as well as south polar stereographic maps from $45^{\circ} \mathrm{S}$ to $90^{\circ} \mathrm{S}$ (Cantor et al. 2001; Wang and Ingersoll 2002). 
MDGM images were obtained online from Ashima Mars Climate Center and an example prior to the onset of the 2001 global dust storm is shown in Figure 6. The MDGM images show the seasonal $\mathrm{CO}_{2}$ ice cap colored white, dust clouds colored yellow to red, and water ice clouds colored white to blue. Most of the atmosphere is dust-free which allows the identification of key surface features. Tharsis Montes can be seen on the left with Olympus Mons as the largest dark circle and clouds capping the southern volcanoes. The Hellas region is a brighter area as a result of dust lifting, located near the bottom right with the south polar cap edge extending north of $60^{\circ} \mathrm{S}$.

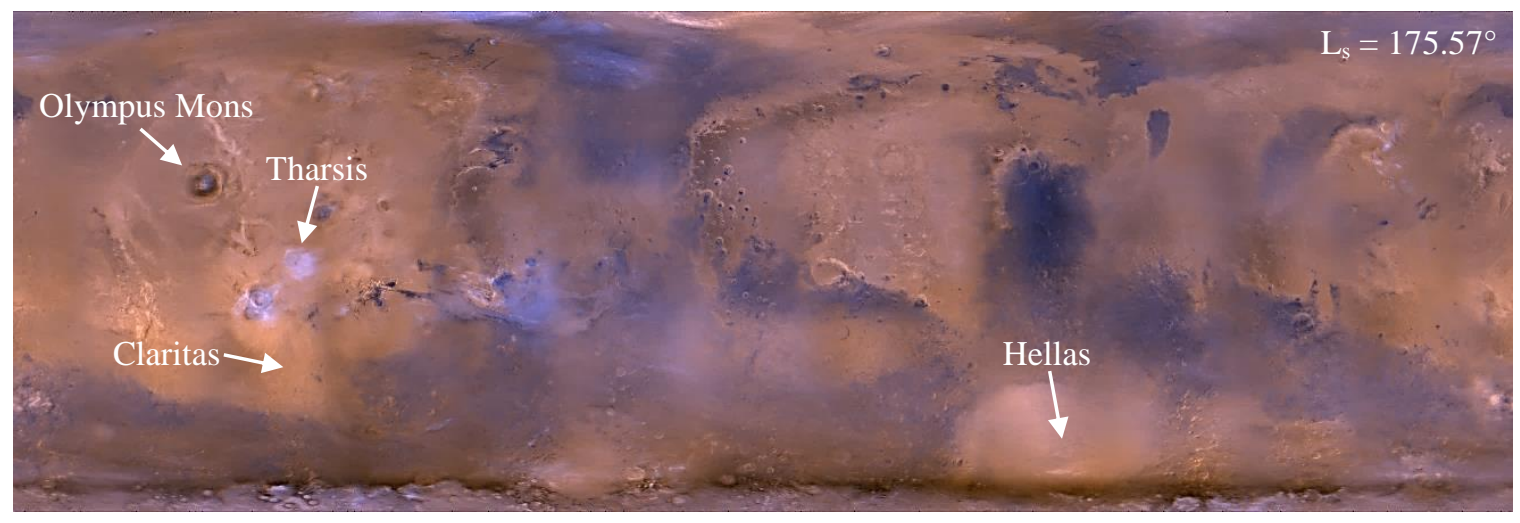

Figure 6. MDGM equatorial image from $60^{\circ} \mathrm{N}$ to $60^{\circ} \mathrm{S}$ prior to the onset of the 2001 global dust storm at $\mathrm{L}_{\mathrm{s}}=175.57^{\circ}$ (MDGM maps courtesy of Ashima Research).

\subsection{Meteorology File}

The minimum meteorological parameters required to operate HYSPLIT's trajectory model include: terrain height or surface pressure, $\mathrm{u}$ and $\mathrm{v}$ wind components, temperature, and moisture. A data file is expected by HYSPLIT for each meteorological 
variable at each specified level and time steps. Input of vertical motion is optional and can be computed with the assumption that an air parcel travels on an isobaric, isosigma, isopycnic, or isentropic surface (Draxler 1999). The meteorological variables from the MGCM are used in the conversion program, mars2arl, which is our modified version of dat2arl. The meteorology quantities provided in mars2arl at upper levels include: $u$ and $v$ winds $\left(\mathrm{m} \mathrm{s}^{-1}\right), \omega\left(\mathrm{hPa} \mathrm{s}^{-1}\right)$, and temperature $(\mathrm{K})$. Mars' atmosphere has little to no moisture, so we set relative humidity to be zero in that meteorology file. Surface quantities provided to mars2arl are surface pressure $(\mathrm{hPa})$ and terrain height $(\mathrm{m})$. Topographic data were acquired from the NASA Planetary Data System from $90^{\circ} \mathrm{N}$ to $90^{\circ} \mathrm{S}$ and $0^{\circ}$ to $360^{\circ}$ longitude with $1^{\circ} \times 1^{\circ}$ resolution.

The starting times chosen for our trajectory calculations are $L_{s}=180,184,188$, and $192^{\circ}$ with 120 hours of data provided at 6-hour intervals. These start times are guided by the evolution of the MY 25 global dust storm as dust storms occurred near Hellas at $\mathrm{L}_{\mathrm{s}} \sim 180^{\circ}$ and Claritas at $\mathrm{L}_{\mathrm{s}} \sim 188^{\circ}$. Once Mars2arl reads the MGCM data, it converts the meteorology data to ARL format for input for the trajectory prediction model.

A major difficulty in modifying dat2arl concerned the mapping of the gridded input data accurately to the internal grid. HYSPLIT allows the transformation of meteorology data to be on a latitude-longitude grid or conformal map projections (Polar, Lambert, Mercator). Mars2arl was developed for a global latitude-longitude grid. The location of the initial data point in the corner of the global grid from the MGCM and topographic data required careful allocating. The MGCM starts at $90^{\circ} \mathrm{S}, 180^{\circ} \mathrm{W}$, while 
the topographic data start at $90^{\circ} \mathrm{N}, 180^{\circ} \mathrm{W}$. In addition, the MGCM's vertical levels start at the top of the atmosphere, while HYSPLIT expects the first vertical level to be near the surface. FORTRAN code was written to make the necessary transformations.

\subsection{Trajectory Prediction Model}

Hymodelt is the main trajectory executable FORTRAN file that calls several subroutines based on the input meteorology file. There is no published chart that describes the order in which these subroutines are called by hymodelt. Appendix B was developed to understand the purpose for each process (blue outline), which files are used to calculate trajectory predications including a description (orange outline), and in what order they are called. For example, the first step includes determining the starting time and number of locations. Hymodelt then calls four files including the file, datset, to set up the date, time, and number of locations. Datset then calls decodi to decode integer input variables. Because of its original development for Earth, planetary and atmospheric constants coded in HYSPLIT required modifying in order to convert the model to Mars (e.g., planetary radius, surface gravity, surface pressure). An investigation of the 50 subroutines in Appendix B ensured a complete transformation to Mars. Some parameters cause no change in the results due to their primary use in the dispersion and concentration simulations of HYSPLIT.

As the model reads the horizontal meteorological data fields in mars2arl, an interpolation of the data to a terrain-following vertical coordinate system ensures an air parcel flows around the topography. The meteorological data are allowed to be input on vertical coordinate systems including pressure-sigma, pressure-absolute, terrain-sigma, or 
a hybrid absolute-pressure-sigma (Draxler and Hess 1997). Sigma levels start with $\sigma=1$ at the surface and decrease to $\sigma=0$ at the top of the atmosphere. A terrain-sigma coordinate system is typically used in highly detailed mesoscale models, and the hybrid coordinate system is used by the ECMWF model. The vertical levels are provided on a pressure-sigma coordinate system with decreasing resolution with increasing altitude through a quadratic relationship:

$$
z=a k^{2}+b k+c
$$

where $\mathrm{z}$ is the height AGL (m), $\mathrm{k}$ is the internal level number, and a,b,c are coefficients that allow decreasing resolution with increasing height ( $30,-25,5$ respectively). Based on the top of the model domain specified by the user, HYSPLIT determines a sufficient internal grid in order to interpolate the meteorology data (Draxler and Hess 1997). The elevation chosen in this study is $60 \mathrm{~km}$.

Any Lagrangian model follows a particle through the calculation of advection. The calculation of the advection of a particle uses an average of the interpolated threedimensional velocity vectors at the first-guess position:

$$
P^{\prime}(t+\Delta t)=P(t)+V(P, t) \Delta t
$$

and the final position:

$$
P(t+\Delta t)=P(t)+\frac{1}{2}\left[V(P, t)+V\left(P^{\prime}, t+\Delta t\right)\right] \Delta t
$$

where $\mathrm{P}(\mathrm{t})$ is the initial position at time $\mathrm{t}, \mathrm{V}(\mathrm{P}, \mathrm{t})$ is the three-dimensional velocity vector, and the integration time step is $\Delta \mathrm{t}$. Higher order integration methods have been shown not to produce greater precision assuming the data are accurately interpolated. 
Trajectories are stopped when a parcel's elevation exceeds the top of the model domain. However, HYSPLIT allows trajectories that intersect the ground to continue to advect on the surface (Draxler and Hess 1997). For parcels that intersect the ground in this study, the remaining trajectory is terminated since dust would most likely settle in this area.

During model execution, various constants not associated with the meteorology file, such as roughness length and land use, were provided to ensure complete modification of the model to Mars. HYSPLIT utilizes a roughness length to calculate the horizontal mean wind speed near the surface. The default roughness length file was replaced with a constant value of $0.01 \mathrm{~m}$ based on VL measurements (Sutton et al. 1978). The purpose of land use is for resuspension calculations and a default land use file for Earth is provided, but the user can select a specific land use from 11 categories (e.g., urban, mixed forest, water) at every grid point. Mars' complex terrain lacks any water or vegetation resulting in a rocky land use characteristic for this study.

Various sources can lead to errors in HYSPLIT's trajectory prediction. A major component of error can arise from the inaccuracy of the model meteorological fields to represent the atmosphere, these are called resolution errors. They can occur during interpolation of meteorological gridded parameters regardless of a high resolution model. Resolution errors are difficult to quantify independently. However, multiple meteorology sources can verify an error. Integration errors involve the integration time step in HYSPLIT and can be minimized with a smaller $\Delta \mathrm{t}$ value. An integration error can be estimated by executing a forward trajectory and then running a backward trajectory from the forward trajectory termination (Draxler and Rolph 2007). 


\section{2001 Global Dust Storm}

\subsection{Storm Progression}

MGS-MOC observations captured the development and decay of a global dust storm that lasted from June to November 2001 in MY 25 and occurred near $\mathrm{L}_{\mathrm{s}}=180^{\circ}$, southern hemisphere spring. This storm was the earliest and most thoroughly recorded global dust storm to date (Strausberg et al. 2005; Cantor 2007). During MY 25, detailed observations were made of Mars' atmosphere as Earth was positioned directly between the Sun and Mars. This alignment is referred to as opposition. Opposition occurs for Earth and Mars every 779 Earth days and the closest proximity occurs when Mars is at perihelion during opposition, which occurs every 15-17 years (Read and Lewis 2004).

Strausberg et al. (2005) observed the evolution of this storm using MGS-MOC and MGS-TES data. Cantor (2007) used MGS-MOC images for this storm to conclude that the storm was initiated by local dust storm activity occurring in seven pulses around the Hellas region. Six transient baroclinic eddies are believed to have initiated these precursor storms, causing significant dust lifting (Noble 2013). The storm was then sustained through several local and regional storms (Strausberg et al. 2005; Cantor 2007).

Figure 7 shows local dust storms around Hellas, at its center, expanding from the basin prior to the global dust storm. The local storms located around Hellas and Malea Planum occurred from $\mathrm{L}_{\mathrm{s}}=176.2-184.6^{\circ}$ (Figures $7 \mathrm{a}-\mathrm{d}$ ) as they spread northward and eastward at $1.5-16.2 \mathrm{~m} \mathrm{~s}^{-1}$ (Cantor 2007). After $\mathrm{L}_{\mathrm{s}}=184.7^{\circ}$, the dust storm rapidly expanded asymmetrically to the east from the Hellas region at speeds ranging from 4-32 $\mathrm{m} \mathrm{s}^{-1}$ reaching Noachis, Arabia, Syrtis, Tyrrhena, Hesperia, Cimmera, and Malea. Note 
the dust-free atmosphere west of Hellas relative to the north and east in Figure 7d. Based on shadows, dust storm heights over the south polar cap were estimated from $21.5-29 \mathrm{~km}$ altitude (Cantor 2007). As the storm began to develop near Hellas at $\mathrm{L}_{\mathrm{s}} \sim 185^{\circ}$, the infrared dust optical depth at $1075 \mathrm{~cm}^{-1}$ for most of the atmosphere measured $\sim 0.1-0.3$ and the core of the dust activity measured greater than one (Smith et al. 2002).
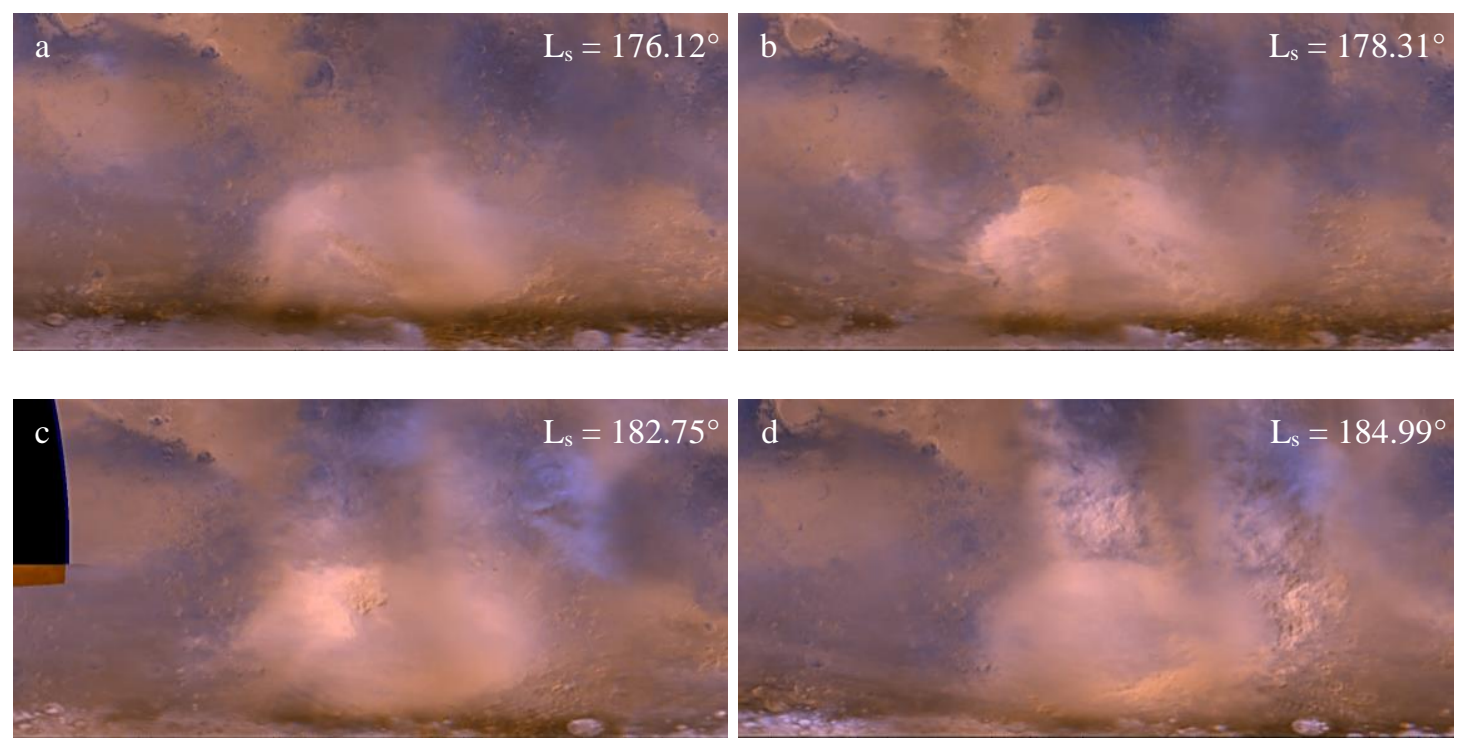

Figure 7. MDGM images of dust storms around Hellas (a) at $\mathrm{L}_{\mathrm{s}}=176.12^{\circ}$ and (b) $178.31^{\circ}$ and the expansion of dust out of the Hellas region (c) at $\mathrm{L}_{\mathrm{s}}=182.75^{\circ}$ and $(\mathrm{d})$ $184.99^{\circ}$.

MDGM south polar stereographic images are shown in Figure 8 during the expansion of dust from Hellas flowing to the south across the south polar cap. The black circles at the image center represent missing data due to polar darkness (Wang and Ingersoll 2002). Figure 8a captures dust activity around the Hellas area, shown as the 
bright region on the right, revealing only the southern half of Hellas. At this time, the south polar cap is dust-free with evidence of water ice clouds around the perimeter of the cap edge. The dust originating from Hellas travels to the south over the polar region by $\mathrm{L}_{\mathrm{s}} \sim 186^{\circ}$ (Figure $8 \mathrm{~b}$ ). After this time, dust is wrapping clockwise around the cap and begins to obscure the polar cap surface (Figures 8c, 8d). By $\mathrm{L}_{\mathrm{s}}=190.65^{\circ}$ (Figure 8e), the dust injection from Hellas toward the south pole decreases as evidenced by the nearly entire cap edge that can be seen through the dust haze. After $L_{s}=191.22^{\circ}$ (Figure 8f), the flow of dust is significantly cut-off from Hellas and a dust haze remains in this area throughout the duration of the global dust storm. 


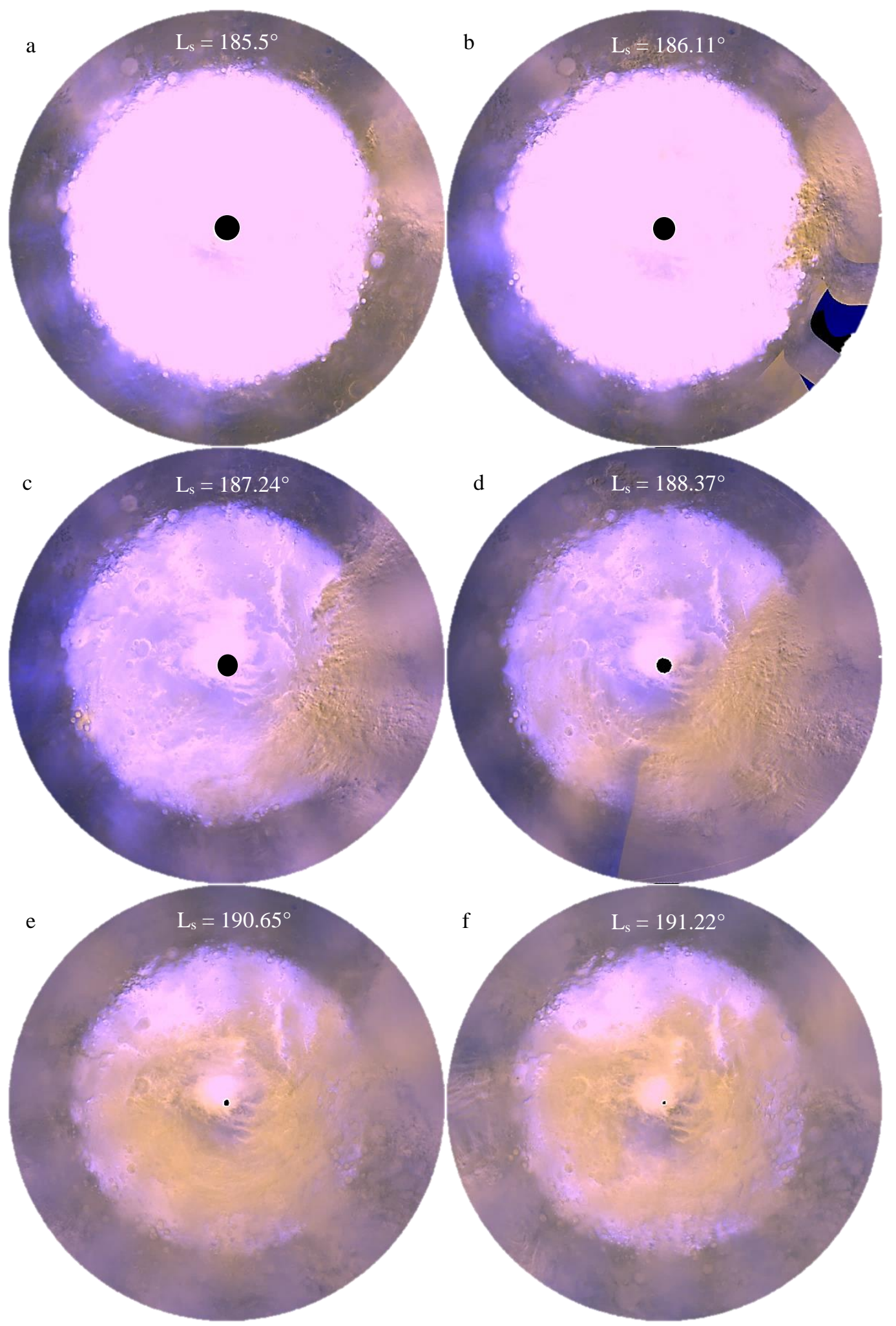

Figure 8. MDGM south polar stereographic images during the expansion from Hellas. 
The Hellas storm activity became planet-encircling in the southern hemisphere by $L_{s}=192.3^{\circ}$ and expanded into the northern hemisphere. The dust shroud obscured the surface between $60^{\circ} \mathrm{N}$ and $59^{\circ} \mathrm{S}$ by $\mathrm{L}_{\mathrm{s}}=197.0^{\circ}$ except for the $20+\mathrm{km}$ high volcanoes in the northern hemisphere. Even though regional storms around the Hellas and Claritas regions continued at $\mathrm{L}_{\mathrm{s}}=200.4^{\circ}$, the optical depth began to diminish as dust settled to the surface. The primary dust clearing occurred until $\mathrm{L}_{\mathrm{s}}=263.4^{\circ}$ while the dust opacity took until $\mathrm{L}_{\mathrm{s}}=304^{\circ}$ to reach a seasonal low (Strausberg et al. 2005; Cantor 2007).

The main direction of propagation for the 2001 global dust storm differed from prior global dust storms. The 2001 storm propagated to the east while previous storms were observed to propagate to the west. Cantor (2007) estimated the general circulation of the atmosphere between $L_{s}=175-199^{\circ}$ in MY 25 to be to the east with wind speeds ranging from 3-32 $\mathrm{m} \mathrm{s}^{-1}$. The dust opacity around Hellas rapidly increased from $\tau \sim 1$ at $\mathrm{L}_{\mathrm{s}}=184.5^{\circ}$ to a peak at $\mathrm{L}_{\mathrm{s}}=199.5^{\circ}$ of $\tau \sim 5.0$ (Cantor 2007).

\subsection{Claritas Storm Activity}

The Hellas storm activity was not the sole contributor to the MY 25 planetencircling storm. The Claritas Fossae region, south of Tharsis, revealed dust activity at $\mathrm{L}_{\mathrm{s}}=188.2^{\circ}$ as shown in Figure 9. Figure 9a shows the Claritas area during the relatively clear atmosphere before the global dust storm. At $\mathrm{L}_{\mathrm{s}}=188.37^{\circ}$ (Figure 9b), a significant plume of dust was located around Claritas, noted with the white circle. The storm expanded south and east into Solis Planum by $\mathrm{L}_{\mathrm{s}}=188.8^{\circ}$ (Figure 9c). The Claritas dust storm became a regional storm on $\mathrm{L}_{\mathrm{s}}=189.6^{\circ}$ extending from Daedalia Planum to Valles Marineris and south to Aonia Terra. After $\mathrm{L}_{\mathrm{s}}=190.5^{\circ}$ (Figure 9d), the Claritas regional 
dust storm expanded north and northeast downslope of the Claritas ridge and across the equator into Lunae Planum (Cantor 2007). The significantly dusty atmosphere in both hemispheres between $60^{\circ} \mathrm{N}$ and $59^{\circ} \mathrm{S}$ from $\mathrm{L}_{\mathrm{s}}=193.4-197^{\circ}$ is shown in Figures 9e, 9f. A strong polar vortex prevented the penetration of storm activity north of $60^{\circ} \mathrm{N}$ (Smith et al. 2002). The Claritas region experienced an increase in optical depth $\sim 2.1$ at $\mathrm{L}_{\mathrm{s}}=196.7^{\circ}$ with a peak $\sim 3.8$ at $\mathrm{L}_{\mathrm{s}}=206.6^{\circ}$ (Cantor 2007). The regional dust storm occurring in this area persisted for 86 sols, the longest time recorded to date for a regional storm (Cantor 2007). 

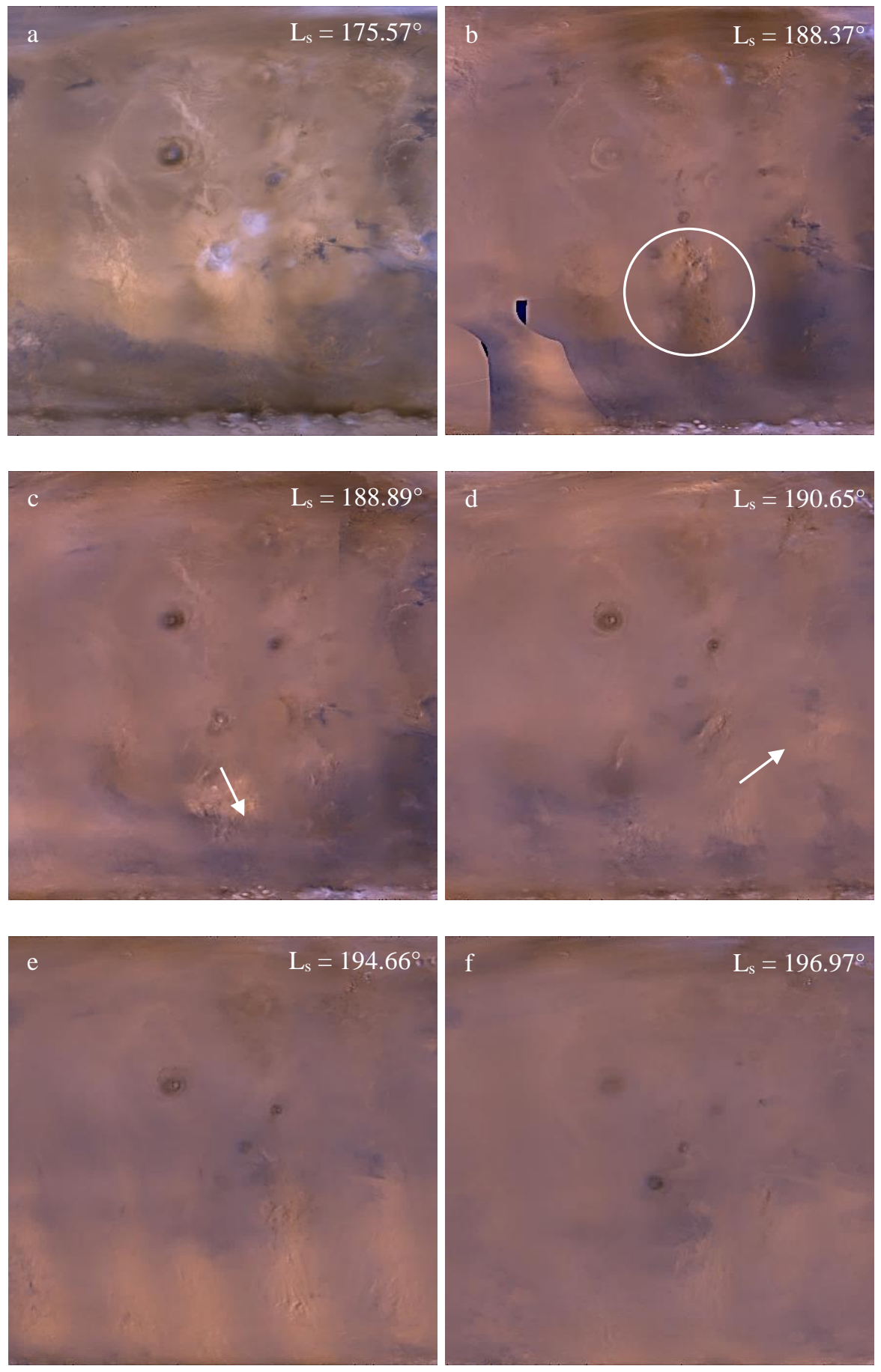

Figure 9. MDGM images of the dust activity around Claritas (a) before the global dust storm at $\mathrm{L}_{\mathrm{s}}=175.57^{\circ}$, (b) at $\mathrm{L}_{\mathrm{s}}=188.37$, (c) 188.89 , (d) 190.65 , (e) 194.66 , and (f) $196.97^{\circ}$. The arrows illustrate the dust flow direction. 
The general circulation patterns for northern hemisphere fall correspond to dust transport shown by the MDGM images during the 2001 global dust storm. MGCM studies during equinox show relatively weak mid-latitude westerlies compared with at solstice, and easterlies near the equator (Haberle et al. 1993). Fenton and Richardson (2001) used MGCM simulations to calculate seasonal average surface winds. During northern hemisphere summer $\left(\mathrm{L}_{s}=90-180^{\circ}\right)$, winds southeast of Hellas flow toward the south polar cap. Surface winds during northern hemisphere fall $\left(\mathrm{L}_{\mathrm{s}}=180-270^{\circ}\right)$ indicate clockwise circulation around Hellas, and the flow around Tharsis is to the south as a result of the topography (Fenton and Richardson 2001).

\section{Trajectory Analysis}

\subsection{Hellas}

A matrix of numerous trajectories throughout Hellas and at several vertical levels was calculated to aid in examining the dust transport from Hellas. Three-dimensional forward trajectories starting on the perimeter and within the Hellas impact crater are shown in Figures 10-13. For brevity, the trajectories shown provide a representative sample for the area. The MGS-MOC topography image is a south polar stereographic projection with the same topography scale as Figure 1. Based on MDGM images during the onset of the global dust storm, the south polar cap edge has little variation, with an estimated extent to $\sim 55^{\circ} \mathrm{S}$ noted by the dashed line. Figures $10-12$ represent trajectories of air parcels lifted to or released at $500 \mathrm{~m}, 1.5 \mathrm{~km}$, and $3 \mathrm{~km}$ AGL starting at $\mathrm{L}_{\mathrm{s}}=184^{\circ}$, corresponding to the initial expansion of dust out of the Hellas region. Air parcel trajectories representing dust transport through the atmosphere assume dust loading 
occurred in that region. Each colored sphere in the figures represents 24 hour increments or $\sim 0.6^{\circ}$ of $\mathrm{L}_{\mathrm{s}}$. The graph below the following figures shows the altitude of each parcel over 120 hours or $\sim 3^{\circ}$ of $L_{s}$.

For parcels released from the western edge of Hellas, the lower level trajectories flow to the north and west and descend to the surface within 24 hours (Figures 10a, 10b). Parcels released at $3 \mathrm{~km}$ move north and east around Hellas, executing clockwise diurnal motions, and they remain aloft over the elevated terrain east of Hellas by $\mathrm{L}_{\mathrm{s}}=187^{\circ}$. Parcels released above this altitude follow a similar path. During the first 24 hours, as the parcels move from a higher elevation at the start to a lower elevation into Hellas, the parcels descend following the terrain (Figure 10b).

Figure 11 is similar to Figure 10 except the starting location is near the center of Hellas. The air parcels are immediately lofted as much as $3 \mathrm{~km}$ above their initial altitude and remain aloft as they travel south from all levels (Figures 11a, 11b). For parcels at $500 \mathrm{~m}$, lighter winds near the surface compared with winds aloft cause the parcel to travel a shorter distance and reach Malea Planum by $\mathrm{L}_{\mathrm{s}}=187^{\circ}$. Dust that is lifted to higher altitudes approaches the cap edge by $\mathrm{L}_{\mathrm{s}} \sim 185.2^{\circ}$ and then continues to flow clockwise around the south polar cap. The parcels remain suspended and slowly increase in altitude until reaching near Aonia Terra by $\mathrm{L}_{\mathrm{s}}=187^{\circ}$.

The trajectories originating from the eastern edge of Hellas are shown in Figure 12a. The trajectories follow a similar path to the trajectories released from the center of Hellas (Figure 11a); the air parcels travel south around the south polar cap ending southwest of Argyre Planitia by $\mathrm{L}_{\mathrm{s}}=187^{\circ}$. Parcels starting at $500 \mathrm{~m}$ generally maintain 
their altitude above the surface while ascending to a maximum of $\sim 2 \mathrm{~km}$ after the first sol. For the upper levels, the air parcels significantly increase in altitude during the last three sols reaching $\sim 9 \mathrm{~km}$ (Figure 12b).

Figure 13a uses the same initial coordinates as Figure 12 for the eastern edge of Hellas, but the trajectories start at $\mathrm{L}_{\mathrm{s}}=188^{\circ}$. This time period corresponds to a shift in wind direction and thus a variation in the movement of dust. The trajectories show a shift from the previous flow to the south to a generally eastward propagation. The lower level parcels flow to the east as they travel upslope out of the basin, and briefly increase in altitude. Within a sol, the parcels quickly fall to the surface (Figure 13b). For parcels originating from $3 \mathrm{~km}$ AGL, parcels flow to the east and move further downwind into Promethei Terra. While the parcel experiences uplift across this area, it rapidly descends and terminates by $\mathrm{L}_{\mathrm{s}} \sim 190.4^{\circ}$ (Figure 13b).

Backward trajectories from the south polar cap verify the source of dust (Figure 14). A trajectory on the opposite side of the south polar cap from Hellas at $4 \mathrm{~km}$ AGL starts at $\mathrm{L}_{\mathrm{s}}=187^{\circ}$ and is traced back to $\mathrm{L}_{\mathrm{s}}=184^{\circ}$ (Figure 14a). The trajectory wraps around the south polar cap back to the eastern side of Hellas from $\sim 12 \mathrm{~km}$ AGL at $\mathrm{L}_{\mathrm{s}}=$ $184^{\circ}$, corresponding to the observations in Figures 11 and 12. The other trajectory in Figure 14a starts near Malea Planum at the surface from $L_{s}=187^{\circ}$ and back to $L_{s}=184^{\circ}$. As dust hits the surface in Malea Planum within the south polar cap, the parcels originate from $\sim 2 \mathrm{~km}$ AGL in Promethei Terra. 


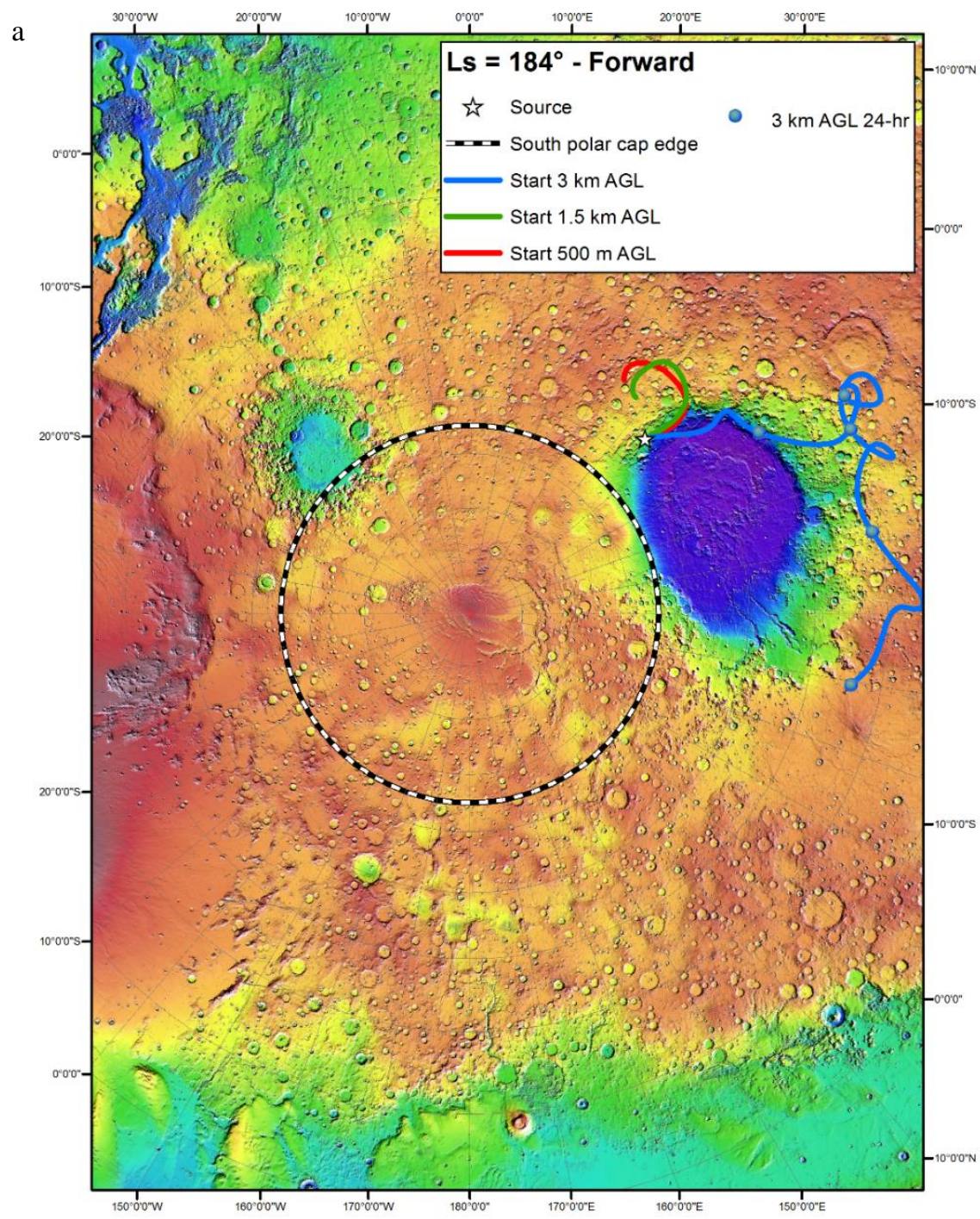

b

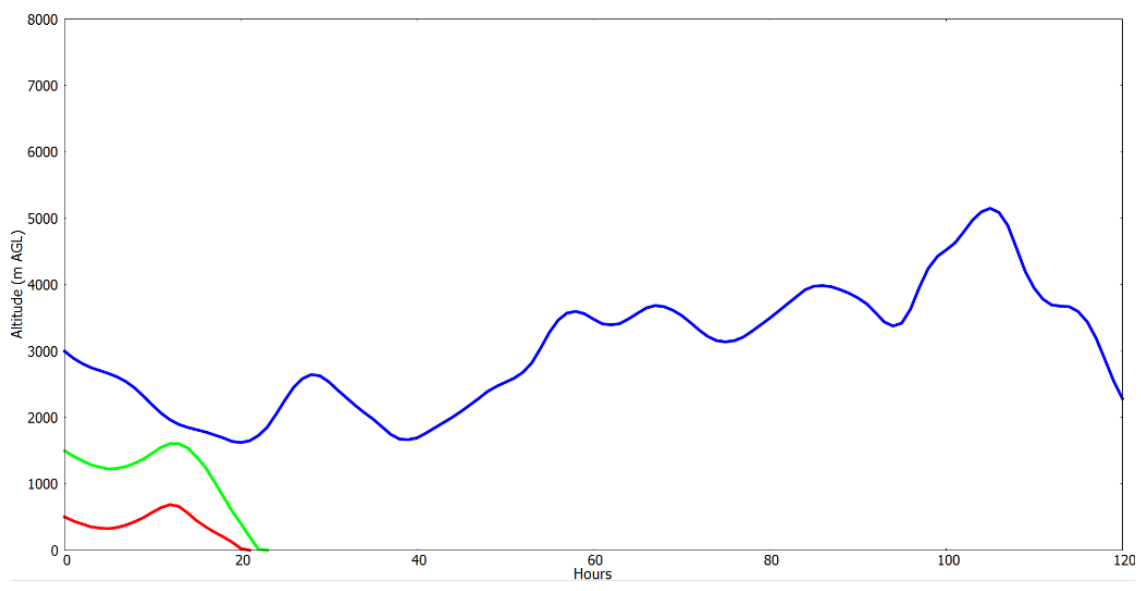

Figure 10. (a) Forward trajectories and (b) altitude for the western Hellas region. 

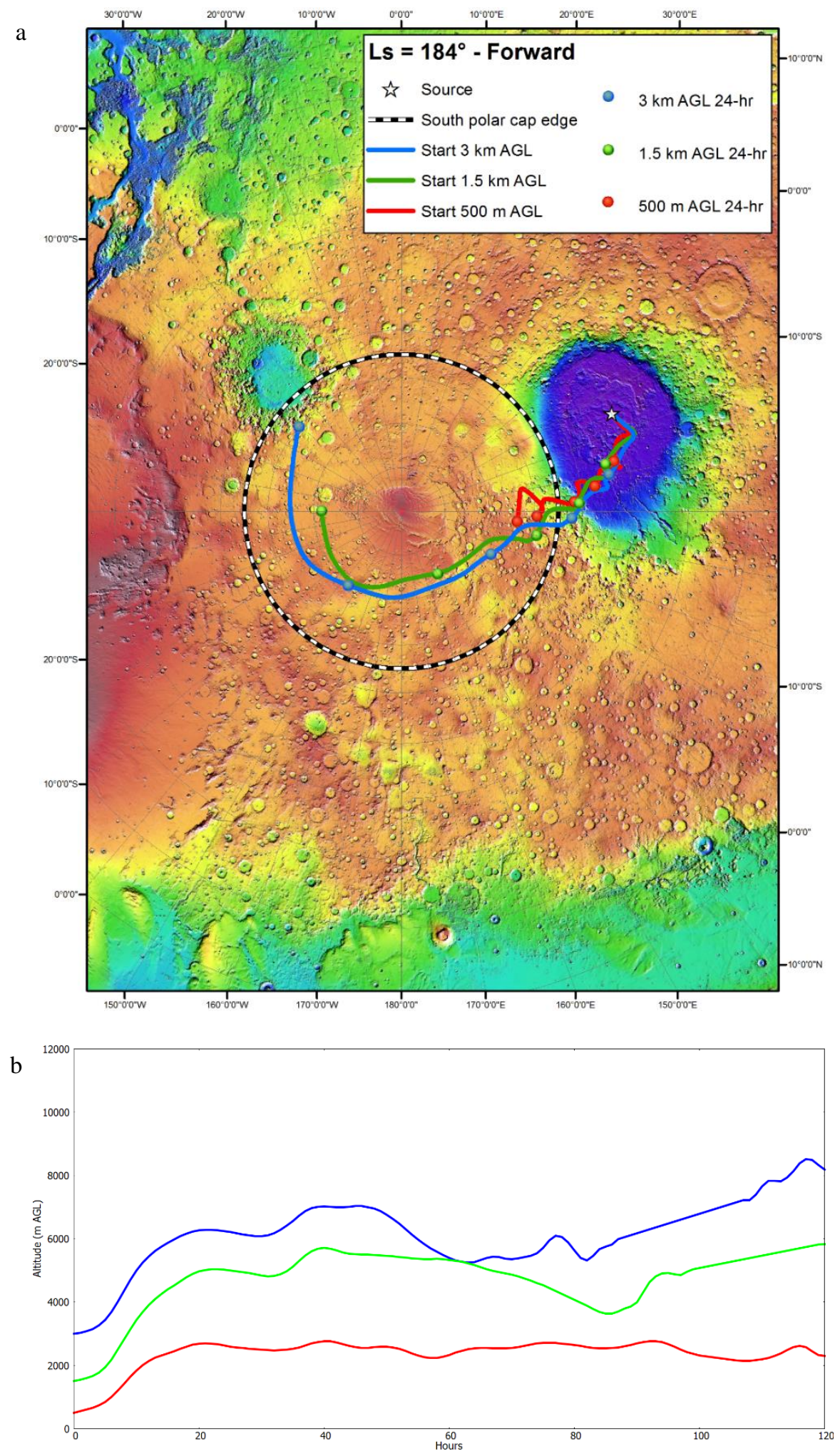

Figure 11. As in Figure 10 but for the central Hellas region. 

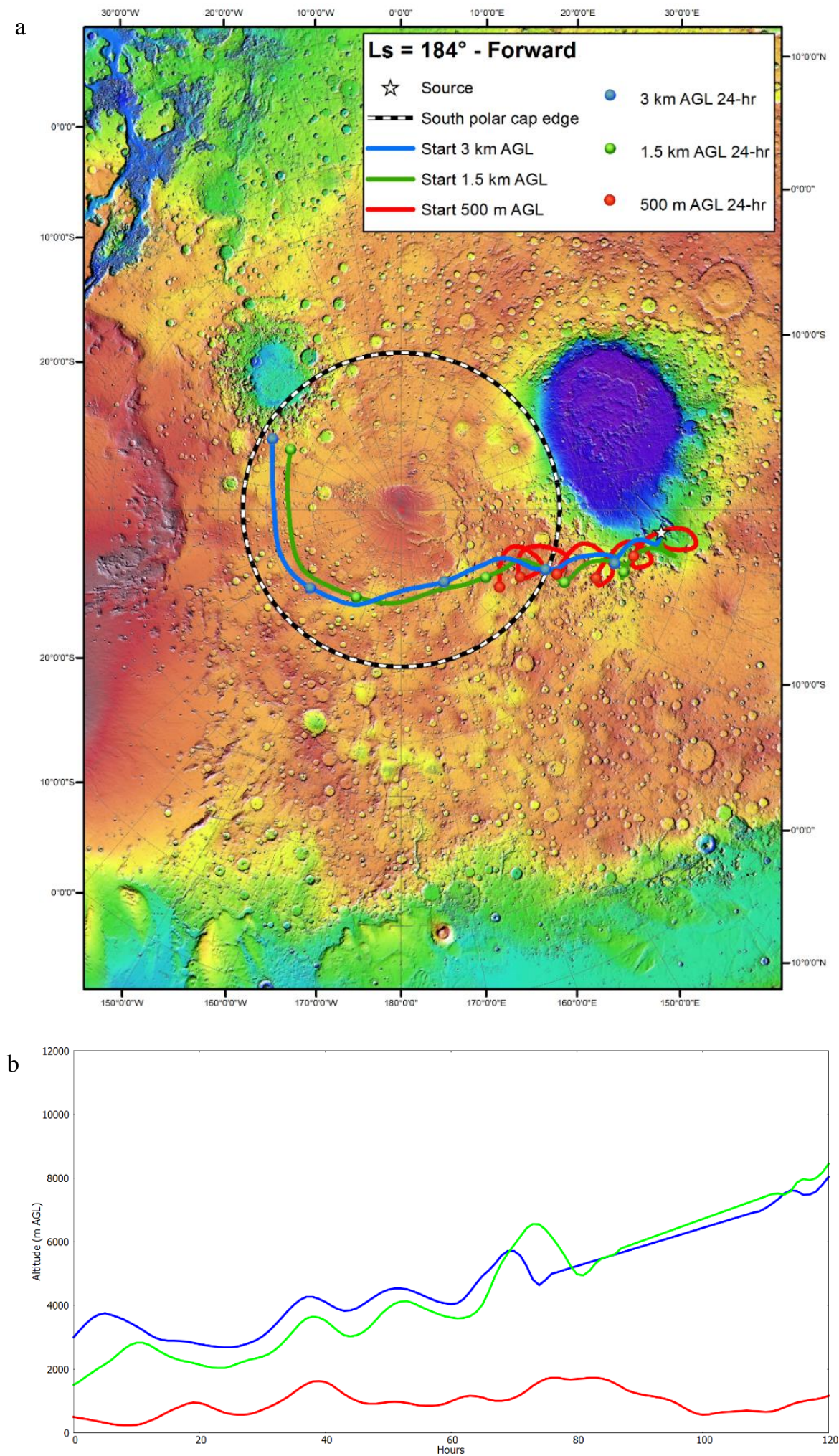

Figure 12. As in Figure 10 but for the eastern Hellas region. 

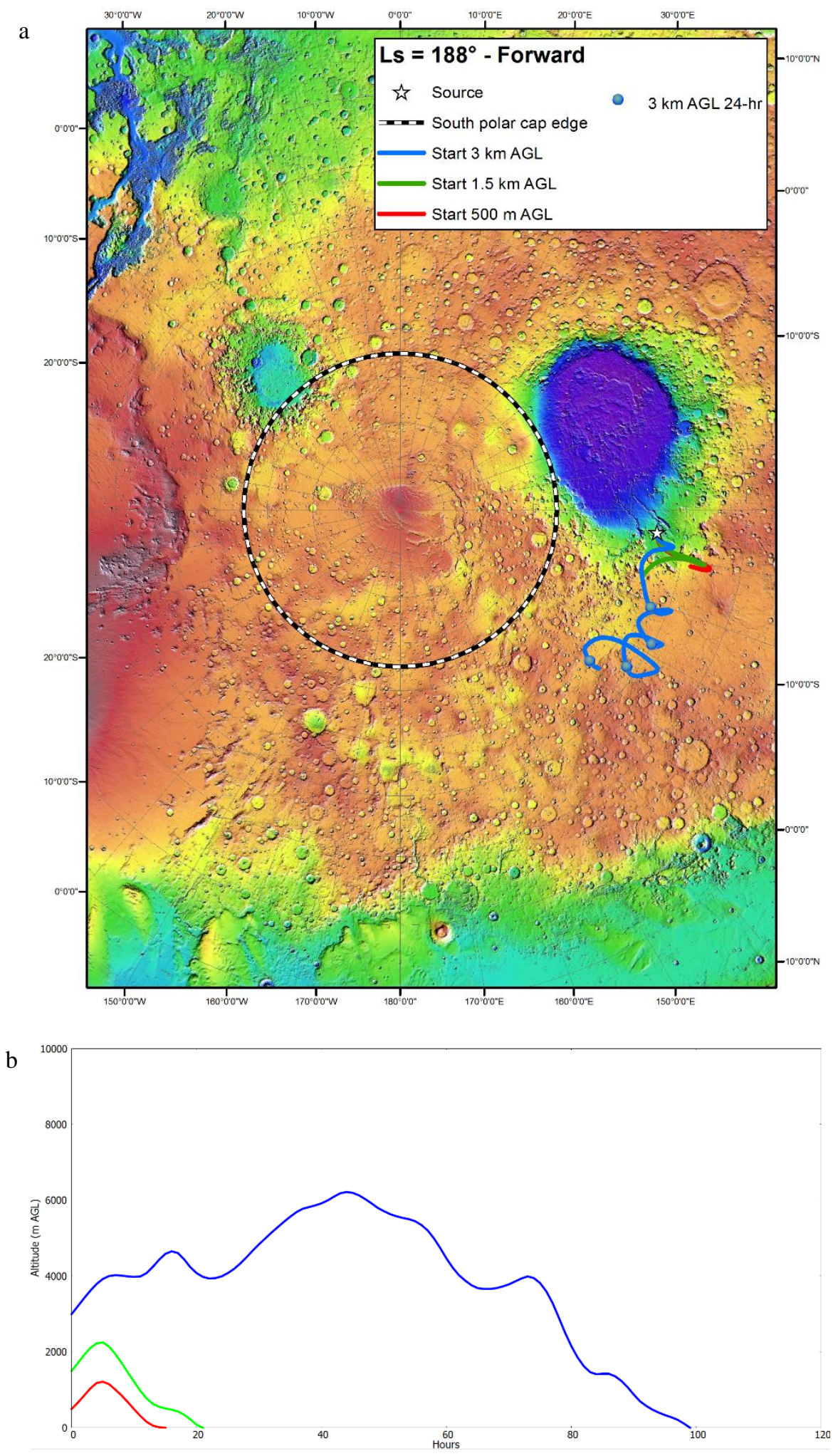

Figure 13. As in Figure 12 but starting at $\mathrm{L}_{\mathrm{s}}=188^{\circ}$. 
a

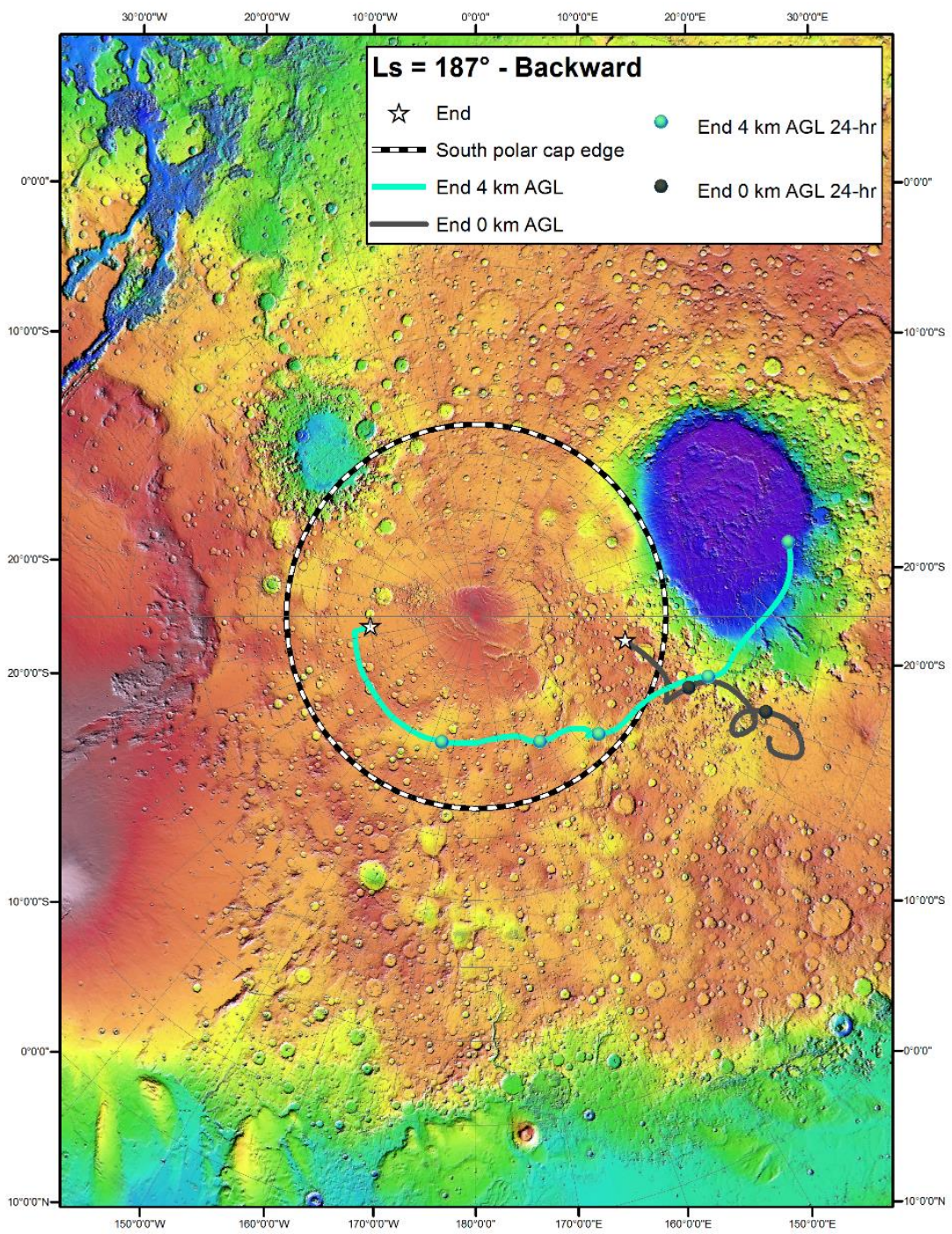

b

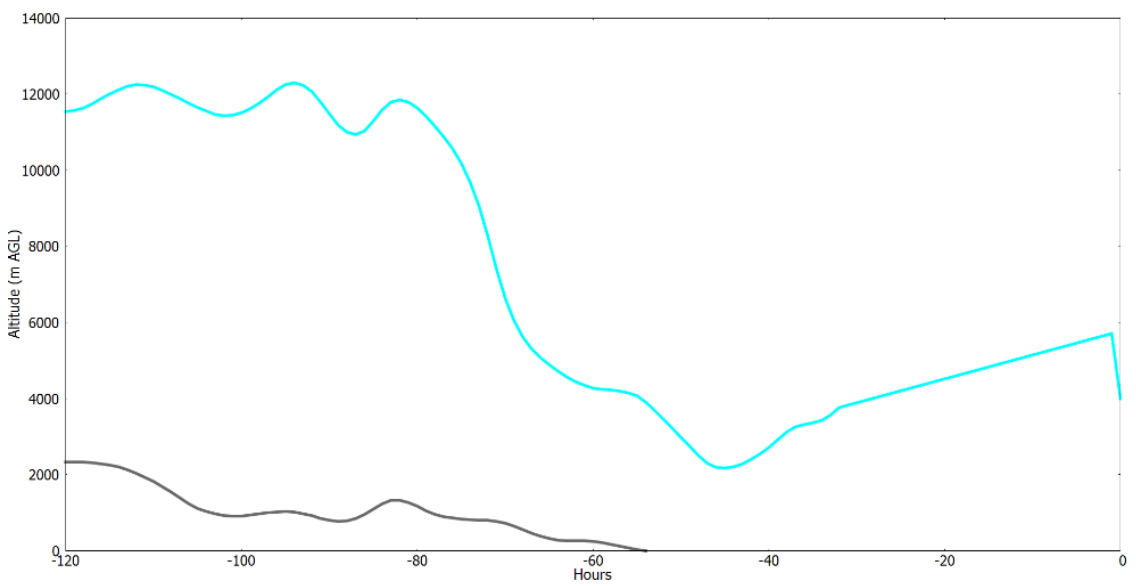

Figure 14. (a) Backward trajectories and (b) altitude around the south polar region. 


\subsection{Claritas}

Forward trajectories from the Claritas region are shown in Figures 15 and 16. The MGS-MOC topography is shown with an equatorial projection with the latitude for the south polar cap edge at $55^{\circ} \mathrm{S}$, the Tharsis volcanoes located on the left, and Valles Marineris on the right. The trajectories around Claritas start at higher altitudes as the result of lower level trajectories immediately descending to the surface.

Figure 15 starts forward trajectories at $\mathrm{L}_{\mathrm{s}}=188^{\circ}$ since the initial dust activity around Claritas began at $\mathrm{L}_{s}=188.2^{\circ}$. The parcels at nearly all levels move to the southeast across Solis Planum and into Aonia Terra (Figure 15a). These parcels ascend throughout the three sols and remain well above their start point (Figure 15b). The parcel starting at $3 \mathrm{~km}$ is lifted to nearly $12 \mathrm{~km}$ by the end of its trajectory.

Starting at $\mathrm{L}_{\mathrm{s}} \sim 189.8^{\circ}$, forward trajectories show the flow changes direction as the air parcels transition to the east and north (Figure 16a). The trajectories flow across Solis Planum, into Valles Marineris, and nearly reach the equator by $L_{s}=191^{\circ}$. Air parcels released below $5 \mathrm{~km}$ reach Valles Marineris and reverse back toward the southwest. At $5+\mathrm{km}$, the parcel does not reverse direction but continues toward the equator. The higher a parcel is released during this time, the further it crosses the equator. Figure 16b shows the parcels increase in altitude as they traverse the Claritas ridge and then slowly decrease in altitude as they follow the downslope terrain.

The potential origin of the dust in Claritas is shown in Figure 17 through the use of backward trajectories from $\mathrm{L}_{\mathrm{s}}=187^{\circ}$ back to $\mathrm{L}_{\mathrm{s}}=184^{\circ}$. This time was chosen due to the Claritas region showing dust activity at $\mathrm{L}_{\mathrm{s}}=188.2^{\circ}$, and this would potentially 
determine the origin of the observed dust activity. The general direction of flow is from the northwest near Amazonis Planitia at most levels shown in Figure 17a. In general, the trajectories begin from a higher altitude and sink into the Claritas region (Figure 17b). The source of air from the northwest would suggest that the Claritas dust activity was a result of local lifting and not due to the advection of dust from the Hellas dust storm. 

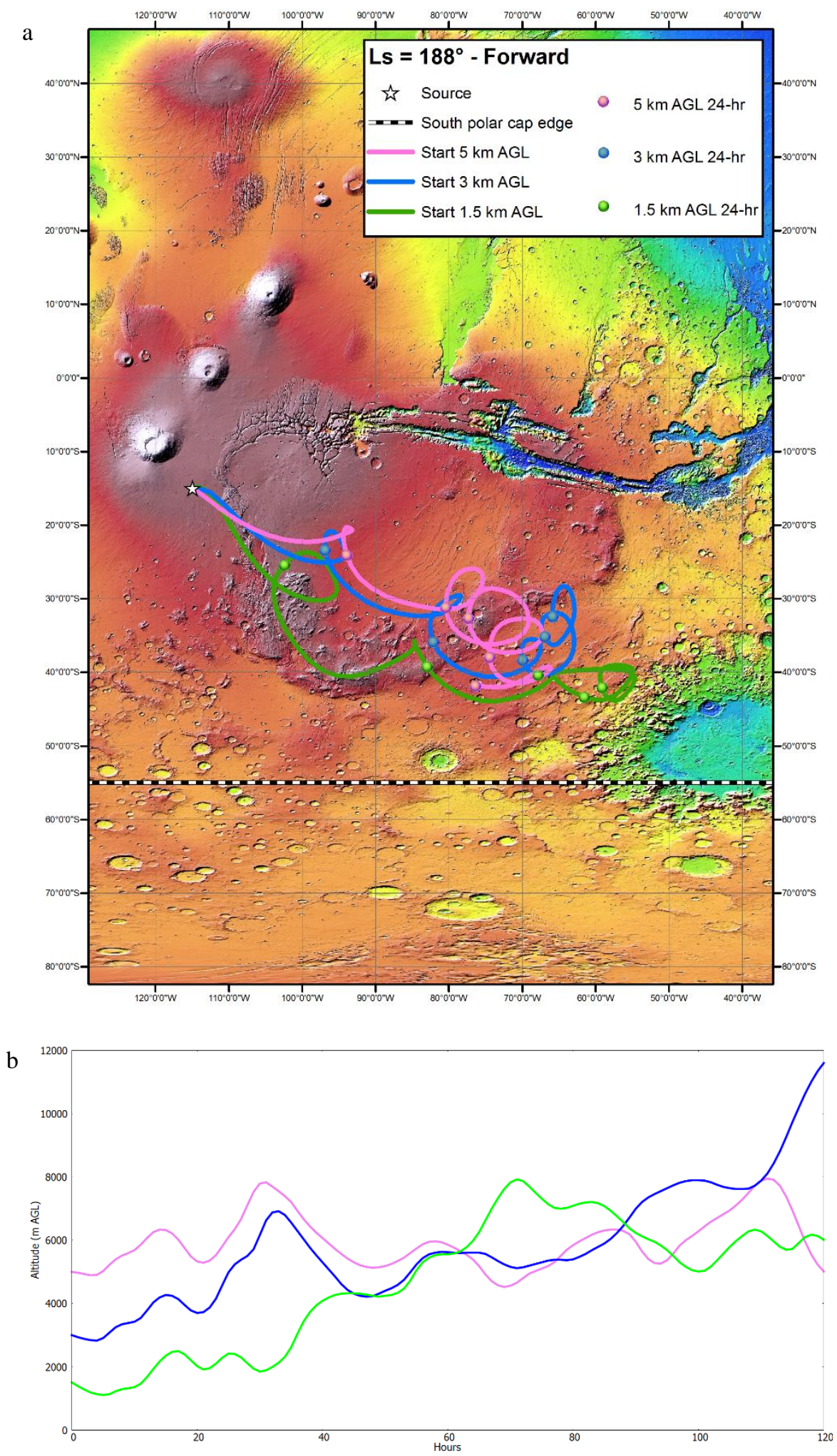

Figure 15. (a) Forward trajectories and (b) altitude for the Claritas region. 
a

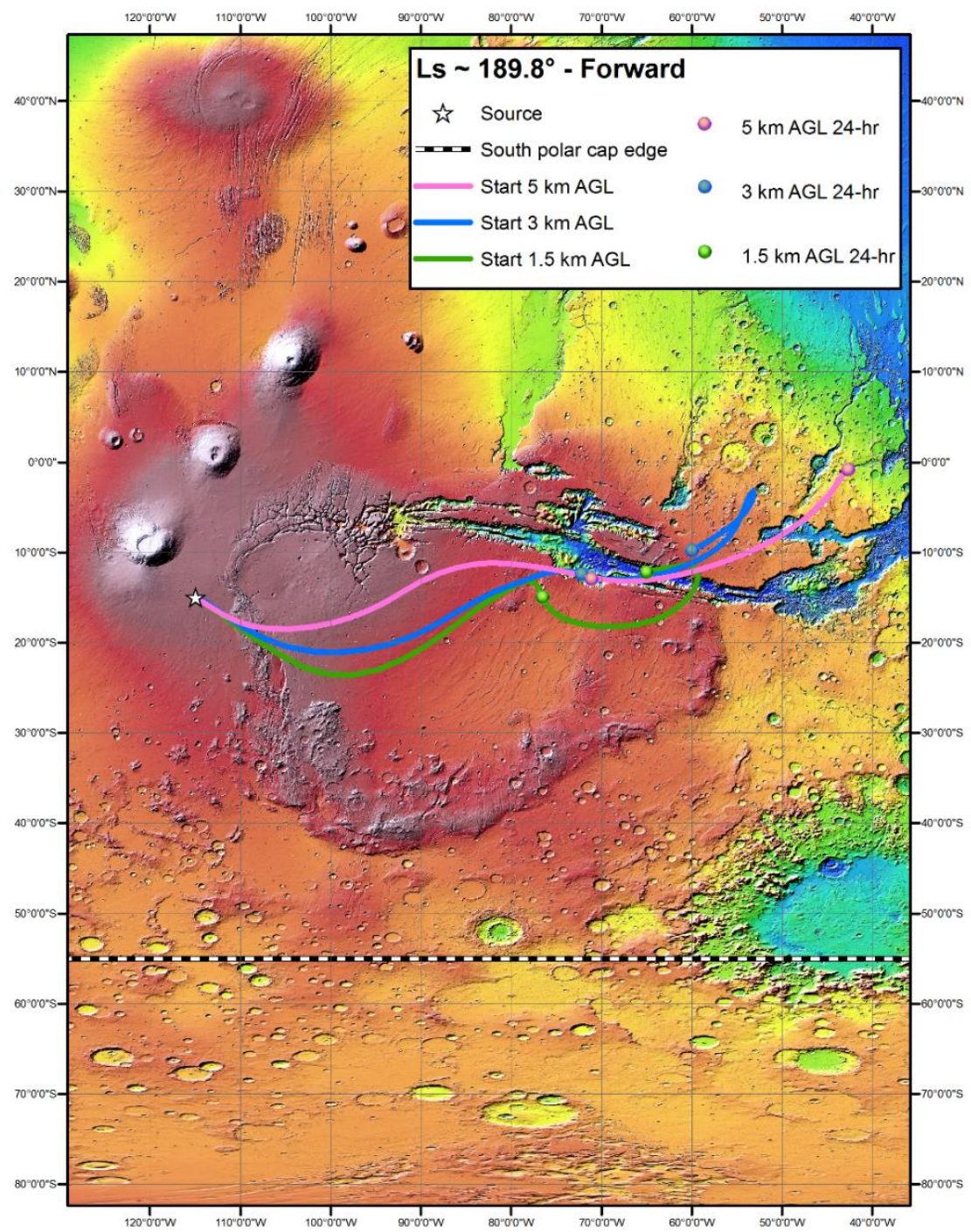

b

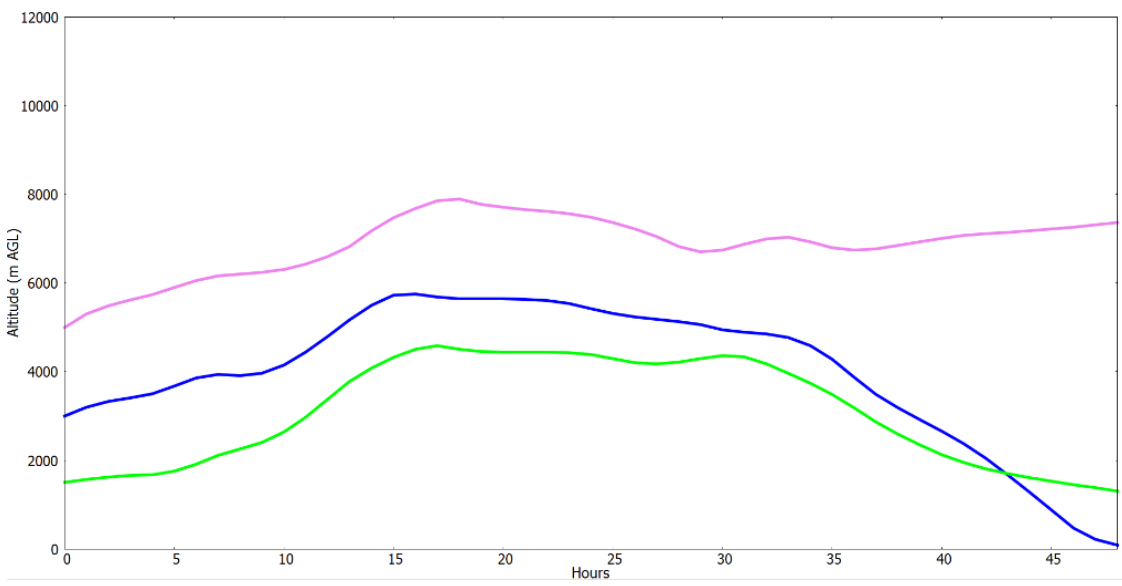

Figure 16. As in Figure 15 but starting at $\mathrm{L}_{\mathrm{s}} \sim 189.8^{\circ}$. 
a

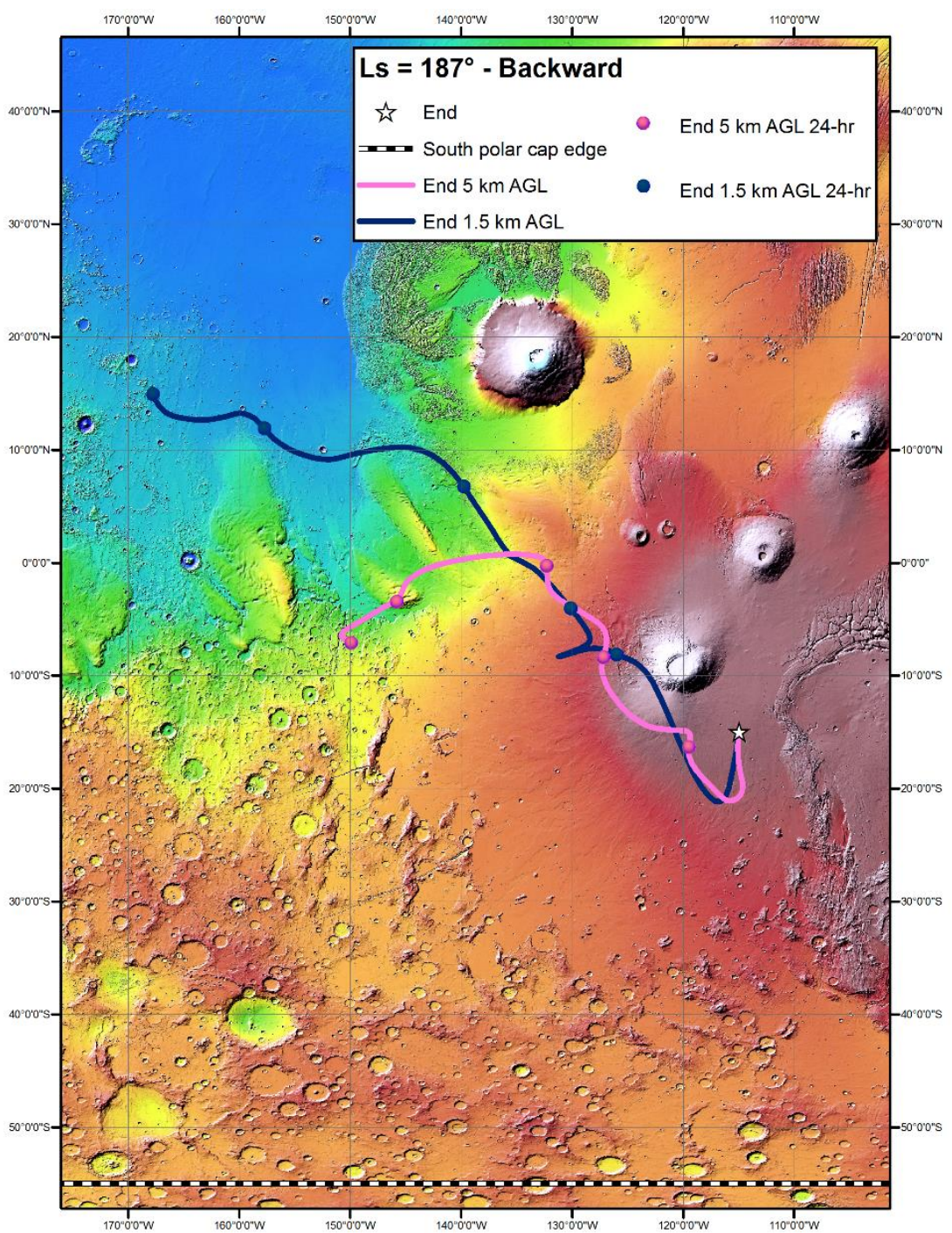

b

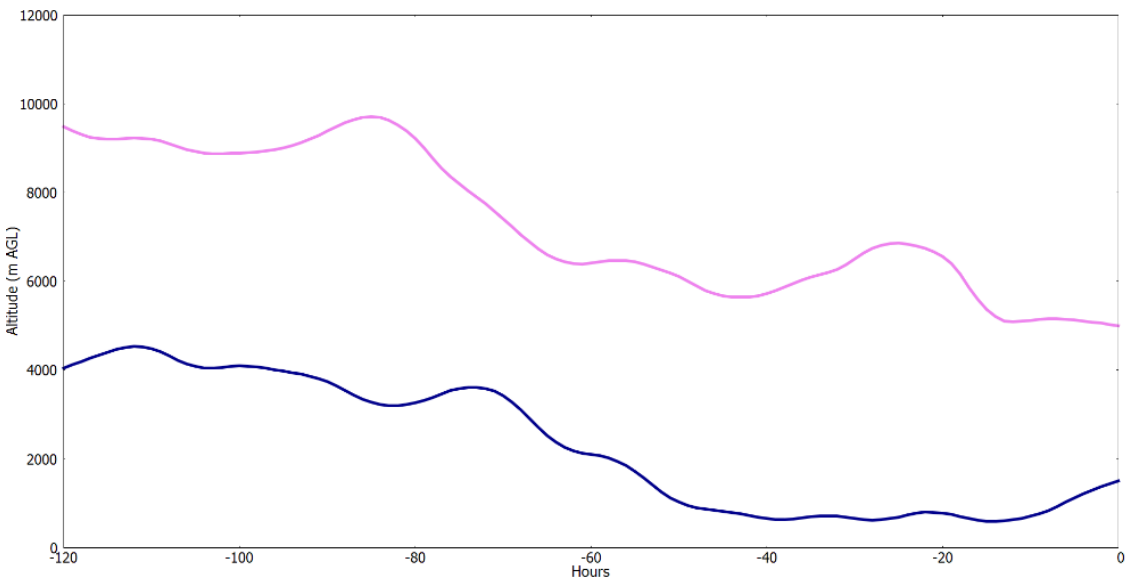

Figure 17. (a) Backward trajectories and (b) altitude for the Claritas region. 


\section{Discussion and Conclusions}

HYSPLIT is a reliable and popular model used in several studies to calculate the transport of aerosols or radionuclides through the Earth's atmosphere. Previous studies modified HYSPLIT for the use of specific model data but not for another planet such as Mars. This study modified the HYSPLIT trajectory prediction model for Mars and showed its effectiveness in replicating satellite imagery observations of dust movement. The modified HYSPLIT accounts for the uniqueness of Mars and enables the input of meteorological data from an MGCM.

Dust plays a crucial role in the atmosphere and climate of Mars, requiring studies beyond the scope of satellite imagery analysis. The modification of HYSPLIT allows the study of air parcel motion and consequently dust transport in the Martian atmosphere. We analyzed the dust transport during the 2001 global dust storm in MY 25 with forward and backward trajectories. The trajectories presented assume dust has been lifted in the area for the winds to advect around the planet. In addition, the dust is assumed to remain aloft and continue along the trajectory without depositing onto the surface. The particular regions of interest included the observed initial location for the storm from the Hellas basin impact crater, and the location of a regional dust storm that helped sustain the global dust storm from Claritas Fossae.

A comparison of MDGM images and trajectories from HYSPLIT provided a validation of our technique. The comparison of MDGM images and trajectories can be subject to inconsistencies because the MDGM images are developed from swaths captured by the MGS-MOC throughout a sol and patched together to span the globe. 
Based on our analysis, the trajectories starting from the central and eastern regions of Hellas correlate with the MDGM observations of dust flow to the south from Hellas. The trajectories then approach the south polar cap edge by $\mathrm{L}_{\mathrm{s}} \sim 185.2^{\circ}$, and circulate around the south pole by $\mathrm{L}_{\mathrm{s}}=187^{\circ}$. The trajectories starting above $1.5 \mathrm{~km}$ (Figures 11a, 12a) continue around the south polar cap further than suggested by the MDGM at $\mathrm{L}_{s}=187.24^{\circ}$ (Figure $8 \mathrm{c}$ ). This difference may be a result of the resolution of the MGCM or because the dust that was advected by the winds had fallen to the surface prior to this time. Forward trajectories from the western edge of Hellas reveal lower level parcels sinking to the surface within a sol (Figure 10). This helps explain the observations of the asymmetric expansion of dust to the east from Hellas instead of to the west. As a result of the circulation around the south polar cap originating from the center and eastern edge of Hellas, the source of dust was from these areas of Hellas and not from the western edge. Forward trajectories starting at $\mathrm{L}_{\mathrm{s}}=184^{\circ}$ from the eastern edge of Hellas (Figure 12a) compared with starting at $\mathrm{L}_{\mathrm{s}}=188^{\circ}$ (Figure 13a) replicate the shift in wind direction seen on MDGM images. Air parcel trajectories show a flow to the south at $\mathrm{L}_{\mathrm{s}}=184^{\circ}$ that changed to a flow to the east by $\mathrm{L}_{\mathrm{s}}=188^{\circ}$. The wind shift occurred because the dust injection from Hellas into the polar region was cut off (Figures $8 \mathrm{e}, 8 \mathrm{f})$.

Backward trajectories at $\mathrm{L}_{\mathrm{s}}=187^{\circ}$ from the south polar cap (Figure 14a) show similar results in Figures 11 and 12 as the dust originated from the eastern side of Hellas at $\mathrm{L}_{\mathrm{s}}=184^{\circ}$. As dust eventually moved east of Hellas into Promethei Terra, backward trajectories from Malea Planum (Figure 14a) show the dust descending and settling on 
the south polar cap. As strong storm activity lifts dust from the surface around Hellas, the dust settling on the south polar cap surface may relate to the PLDs observations. These trajectories provide evidence for a global dust storm transporting dust to the poles and possibly contributing to the observed dust layering.

The MDGM images revealed dust activity around Claritas at $\mathrm{L}_{\mathrm{s}}=188^{\circ}$ but an important question to address is: was the Claritas dust storm due to local storm activity or did the dust originate from the expansion of the Hellas dust storm to the east? The forward trajectories from Hellas at $\mathrm{L}_{\mathrm{s}}=188^{\circ}$ (Figure 13) reveal air parcels flow to the east and descend to the surface several kilometers west of Claritas. This evidence indicates that the dust activity observed around Claritas did not correspond to the dust activity occurring at Hellas. In addition, backward trajectories starting at $\mathrm{L}_{\mathrm{s}}=187^{\circ}$ from Claritas (Figure 17) reveal air parcels coming from the northwest near Amazonis Planitia. These results suggest the Hellas and Claritas storm activity were independent local events.

In regards to the Claritas dust storm progression, forward trajectories from $\mathrm{L}_{\mathrm{s}}=$ $188^{\circ}$ starting at Claritas are comparable to the MDGM observations of a flow to the southeast into Aonia Terra (Figure 15a). After $\mathrm{L}_{\mathrm{s}}=190.5^{\circ}$, the flow changes to the northeast, crossing the equator probably due to enhanced Hadley cell circulation (Haberle et al. 1993). Forward trajectories from $\mathrm{L}_{\mathrm{s}} \sim 189.8^{\circ}$ (Figure 16a) follow this pattern to the northeast with air parcels starting at $5 \mathrm{~km}$ and continuing into Lunae Planum. As the regional dust storm lofted dust to higher altitudes, dust may have been entrained into the ascending branch of the Hadley cell circulation located in the southern hemisphere at this 
time (Figure 3a). The dust could then be transported to the north and sink to the surface in the descending branch of the Hadley cell in the northern hemisphere. This hemispheric redistribution of dust may have contributed to the dust storm becoming global.

Uncertainties can be introduced by the assumptions used in this study including massless dust particles assumed to have been lifted from the surface and following along the trajectory. Any dust particle has a mass that will cause the particle to fall to the surface by itself. However, observations show dust can be lofted high in the atmosphere and remain aloft for long periods of time. The trajectories presented represent the general flow of dust capable of remaining suspended in the atmosphere. Most large particles likely fell to the surface prior to the end of their trajectory.

Particular times of air parcel motions were nearly identical to the MDGM images but variations in the time could be a result of the coarse resolution of the MGCM. The improvement in the grid spacing of $7.5^{\circ}$ latitude and $9^{\circ}$ longitude would be advantageous for future studies to compare to our results. Other possible errors could include horizontal and vertical interpolation errors of meteorological parameters made in the HYSPLIT model. The ability of our customized HYPSLIT to replicate observations made in the MDGM images can help future studies analyze dust transport in the Martian atmosphere and answer questions concerning dust storm events and the PLDs. 


\section{REFERENCES}

Anderson, E. M., and C. B. Leovy, 1978: Mariner 9 television limb observations of dust and ice hazes on Mars. J. Geophys. Res., 35, 723-734.

Barlow, N., 2008: Mars: An introduction to its interior, surface, and atmosphere. Cambridge University Press, 281 pp.

Basu S., M. I. Richardson, and R. J. Wilson, 2004: Simulations of the Martian dust cycle with the GFDL Mars GCM. J. Geophys. Res., 109, E11006.

Calvin, W. M., and T. M. Martin, 1994: Spatial variability in the seasonal south polar cap of Mars. J. Geophys. Res., 99, 21143-21152.

Cantor, B. A., 2007: MOC observations of the 2001 Mars planet-encircling dust storm. Icarus, 186, 60-96.

Cantor, B. A., M. Caplinger, P. James, and M. J. Wolff, 2001: Martian dust storms: 1999 Mars Orbiter Camera observations. J. Geophys. Res., 106, 23653-23687.

Cantor, B. A., and Coauthors, 2008: Observations of the Martian atmosphere by MROMARCI, an overview of 1 Mars year. Third International Workshop on the Mars atmosphere: Modelling and Observations, Wlliamsburg, Virginia.

Choi, D. S., and C. M. Dundas, 2011: Measurements of Martian dust devil winds with HiRISE, Geophys. Res. Lett., 38, L24206.

Clancy, R. T., B. Sandor, M. Wolff, P. Christensen, M. Smith, J. Pearl, B. Conrath, and R.Wilson, 2000: An intercomparison of ground-based millimeter, MGS TES, and Viking atmospheric temperature measurements- Seasonal and interannual variability of temperatures and dust loading in the global Mars atmosphere. J. Geophys. Res., 105, 9553-9571.

Collins, M., and I. N. James, 1995: Regular baroclinic transient waves in a simplified global circulation model of the Martian atmosphere. J. Geophys. Res., 100, 14421-14432.

Draxler, R. R., 1999: HYSPLIT4 user's guide. NOAA Tech. Memo. ERL ARL-230, NOAA Air Resources Laboratory, Silver Spring, MD.

Draxler, R. R. and A. D. Taylor, 1982: Horizontal dispersion parameters for long-range transport modeling. J. Appl. Meteor., 21, 367-372.

Draxler, R. R., and G. D. Hess, 1997: Description of the HYSPLIT_4 modeling system. 
NOAA Tech. Memo. ERL ARL-224, NOAA Air Resources Laboratory, Silver Spring, MD, $24 \mathrm{pp}$.

Draxler, R. R., and G. D. Rolph, 2007: HYSPLIT-WEB Short Course. National Air Quality Conference, Orlando, Florida.

Draxler, R. R, and G. D. Rolph, 2012: Evaluation of the Transfer Coefficient Matrix (TCM) approach to model the atmospheric radionuclide air concentrations from Fukishima. J. Geophys. Res., 117.

Draxler, R. R. and G. D. Rolph, 2015: HYSPLIT (HYbrid Single-Particle Lagrangian Integrated Trajectory) Model access via NOAA ARL READY Website (http://ready.arl.noaa.gov/HYSPLIT.php). NOAA Air Resources Laboratory, Silver Spring, MD.

Draxler, R. R., and Coauthors, 2013: The World Meteorological Organization's Evaluation of Meteorological Analyses for the Radionuclide Dispersion and Deposition from the Fukushima Daiichi Nuclear Power Plant Accident. Third meeting of WMO on meteorological analyses for Fukushima-Daiichi nuclear power plant accident. Vienna, Austria.

Dreher, J., 2009: Configuring the HYSPLIT model for National Weather Service Forecast Office and Spaceflight Meteorology Group Applications. NASA Contractor Report CR-2009-214764, 36 pp.

Eslinger, P., and Coauthors, 2014: Source Term Estimation of Radioxenon Released from the Fukushima Dai-Ichi Nuclear Reactors Using Measured Air Concentrations and Atmospheric Transport Modeling. Journal of Environmental Radioactivity, 127, 127-132.

Fenton, L. K., and M. I. Richardson, 2001: Martian surface winds: Insensitivity to orbital changes and implications for aeolian processes. J. Geophys. Res., 106, 32,88532,902 .

Giuranna, M., G. Hansen, V. Formisano, L. Zasova, A. Maturilli, D. Grassi, and N. Ignatiev, 2007: Spatial variability, composition, and thickness of the seasonal north polar cap of mars in mid-spring. Planetary and Space Science, 55, 13281345 .

Haberle, R. M., J. B. Pollack, J. R. Barnes, R. W. Zurek, C. B. Leovy, J. Murphy, H. Lee, and J. Schaeffer, 1993: Mars Atmospheric Dynamics as Simulated by the NASA Ames General Circulation Model 1. The Zonal-Mean Circulation. J. Geophys. Res., 98, 3093-3123. 
Hess, S. L., R. M. Henry, C. B. Leovy, J. A. Ryan, and J. E. Tillman, 1977: Meteorological results from the surface of Mars: Viking 1 and 2, J. Geophys. Res., 82, 4559-4574.

Hourdin, F., 1992: A new representation of the $\mathrm{CO}_{2} 15 \mu \mathrm{m}$ band for a Martian general circulation model. J. Geophys. Res., 97, 18319-18335.

Housiadas, C., 1999: Cm-hysplit: A software capability forresponse in nuclear emergencies. Tech. rep., Institute of Nuclear Technology and Radiation Protection.

Hvidberg, C. S., K. E. Fishbaugh, M. Winstrup, A. Svensson, S. Byrne, and K. E. Herkenhoff, 2012: Reading the climate record of the martian polar layered deposits. Icarus, 221, 405-419.

Jakosky, B. M., and Coauthors, 2015: The Mars Atmosphere and Volatile Evolution (MAVEN) Mission. Space Sci. Rev.

Kahanpää, H., and Coauthors, 2014: Convective vortices at the MSL landing site. Fifth International Workshop on the Mars atmosphere: Modelling and Observations, Oxford, UK.

Kahre, M. A., and R. M. Haberle, 2010: Mars $\mathrm{CO}_{2}$ cycle: Effects of airborne dust and polar cap ice emissivity. Icarus, 207, 648-653.

Kahre, M. A., J. R. Murphy, and R. M. Haberle, 2006: Modeling the Martian dust cycle and surface dust reservoirs with the NASA Ames general circulation model. J. Geophys. Res., 111, E06008.

Kieffer, H. H., B. M. Jakosky, C. W. Snyder, and M. S. Matthews, 1992: Mars. The University of Arizona Press, 1498 pp.

Leovy, C., 2001: Weather and climate on Mars. Nature, 412, 245-249.

Leovy, C. B., and Y. Mintz, 1969: Numerical simulations of the atmospheric circulation and climate of Mars. J. Geophys. Res., 26, 1167-1190.

Magalhães, J. A., J. T. Schofield, and A. Seiff, 1999: Results of the Mars Pathfinder atmospheric structure investigation. J. Geophys. Res., 104, 8943-8955.

Martin, T. Z., and R. W. Zurek 1993: An analysis of the history of dust activity on Mars. J. Geophys. Res., 98, 3221-3246.

Montabone, L., and Coauthors, 2015: Eight-year Climatology of Dust Optical Depth on 
Mars. Icarus, 251, 65-95.

Murray, B. C., L. A. Soderblom, J. A. Cutts, R. P. Sharp, D. J. Milton, and R. B. Leighton, 1972: Geological framework of the south polar layered region of Mars. Icarus, 17, 328-345.

Noble, J., 2013: Integration of Mars Global Surveyor observations of the MY 25 planetencircling dust storm on Mars: implications for atmospheric dynamics and modeling. M. S. thesis, Department of Meteorology and Climate Science, San José State University, 116 pp.

Read, P. L., and S. R. Lewis, 2004: The Martian climate revisited: atmosphere and environment of a desert planet. Springer-Praxis Books, 326 pp.

Reiss, D., A. Spiga, and G. Erkeling, 2014: The horizontal motion of dust devils on Mars derived from CRISM and CTX/HiRISE observations. Icarus, 227, 8-20.

Richardson, M. I., and R. J. Wilson, 2002: A topographically forced asymmetry in the martian circulation and climate. Nature, 416, 298-301.

Rolph, G. D., 2015. Real-time Environmental Applications and Display sYstem (READY) Website (http://ready.arl.noaa.gov). NOAA Air Resources Laboratory, Silver Spring, MD.

Ryan, J. A., and R. M. Henry, 1979: Mars Atmospheric Phenomena During Major Dust Storms, as Measured at Surface. J. Geophys. Res., 84, 2821-2829.

Ryan, J. A., and R. D. Lucich, 1983: Possible Dust Devils, Vortices on Mars. J. Geophys. Res., 88, 11,005-11,011.

Schofield, J., and Coauthors, 1997: The Mars Pathfinder atmospheric structure investigation/meteorology (ASI/MET) experiment. Science, 278, 1752-1758.

Smith, D. E., and Coauthors, 2001: Mars Orbiter Laser Altimeter: Experiment summary after the first year of global mapping of Mars. J. Geophys. Res., 106, 23,68923,722 .

Smith, M. D., 2009: THEMIS observations of Mars aerosol optical depth from 20022008. Icarus, 202, 444-452.

Smith, M. D., B. J. Conrath, J. C. Pearl, and P. R. Christensen, 2002: Thermal Emission Spectrometer Observations of Martian Planet-Encircling Dust Storm 2001A. Icarus, 157, 259-263. 
Stanzel, C. M., M. Pätzold, D. A. Williams, P. L. Whelley, R. Greeley, G. Neukum, and The HRSC Co-Investigator Team, 2008: Dust devil speeds, directions of motion and general characteristics observed by the Mars Express High Resolution Stereo Camera, Icarus, 197, 39-51.

Strausberg, M. J., H. Wang, M. I. Richardson, S. P. Ewald, and A. D. Toigo, 2005: Observations of the initiation and evolution of the 2001 Mars global dust storm. J. Geophys. Res., 110, E02006.

Sutton, J. L., C. B. Leovy, and J. E. Tillman, 1978: Dirunal variations of the martian surface layer meteorological parameters during the first 45 sols at two Viking Lander sites. J. Geophys. Res., 35, 2346-2355.

Takahashi, Y. O., H. Fujiwara, H. Fukunishi, M. Odaka, Y. Hayashi, and S. Watanabe, 2003: Topographically induced north-south asymmetry of the meridional circulation in the Martian atmosphere. J. Geophys. Res., 108, 5018.

Vasavada, A. R., and Coauthors, 2014: Overview of the Mars Science Laboratory mission: Bradbury Landing to Yellowknife Bay and beyond. J. Geophys. Res. Planets, 119, 1134-1161.

Wang, H., and A. P. Ingersoll, 2002. Martian clouds observed by Mars Global Surveyor Mars Orbiter Camera. J. Geophys. Res., 107, 5078.

Wang, H., and M. I. Richardson, 2015: The origin, evolution, and trajectory of large dust storms on Mars during Mars years 24-30 (1999-2011). Icarus, 251, 112-127.

Wilson, R. J., and K. Hamilton, 1996: Comprehensive model simulation of thermal tides in the Martian atmosphere. J. Geophys. Res., 53, 1290-1326.

Zalucha, A. M., 2014: The effect of dust on the Martian Hadley cells. Fifth International Workshop on the Mars atmosphere: Modelling and Observations, Oxford, UK.

Zalucha, A. M., R. Plumb, and R. J. Wilson, 2010: An Analysis of the Effect of Topography on the Martian Hadley Cells. J. Geophys. Res., 67, 673-693.

Zuber, M. T., D. E. Smith, S. C. Solomon, D. O. Muhleman, J. W. Head, B. Garvin, J. B. Abshire, and J. L. Bufton, 1992: The Mars Observer Laser Altimeter Investigation. J. Geophys. Res., 97, 7781-7797.

Zurek, R. W., 1982: Martian great dust storms: An update, Icarus, 50, 288-310.

Zurek, R. W., and L. J. Martin, 1993: Interannual variability of planet-encircling dust 
storms on Mars. J. Geophys. Res., 98, 3247-3259. 


\section{APPENDIX A: Acronyms}

AGL

ARL

$\mathrm{CO}_{2}$

HYSPLIT

$\mathrm{L}_{\mathrm{s}}$

MCS

MDGM

MGCM

MGS

MOLA

MOC

MPF

MRO

MSL

MY

NASA

PLD

TES

VL
Above ground level

Air Resources Laboratory

Carbon dioxide

Hybrid Single Particle Lagrangian Integrated Trajectory

Solar longitude

Mars Climate Sounder

Mars Daily Global Map

Mars General Circulation Model

Mars Global Surveyor

Mars Orbiter Laser Altimeter

Mars Orbiter Camera

Mars Pathfinder

Mars Reconnaissance Orbiter

Mars Science Laboratory

Martian year

National Aeronautics and Space Administration

Polar layered deposit

Thermal Emission Spectrometer

Viking lander 


\section{APPENDIX B: HYSPLIT Call Chart}

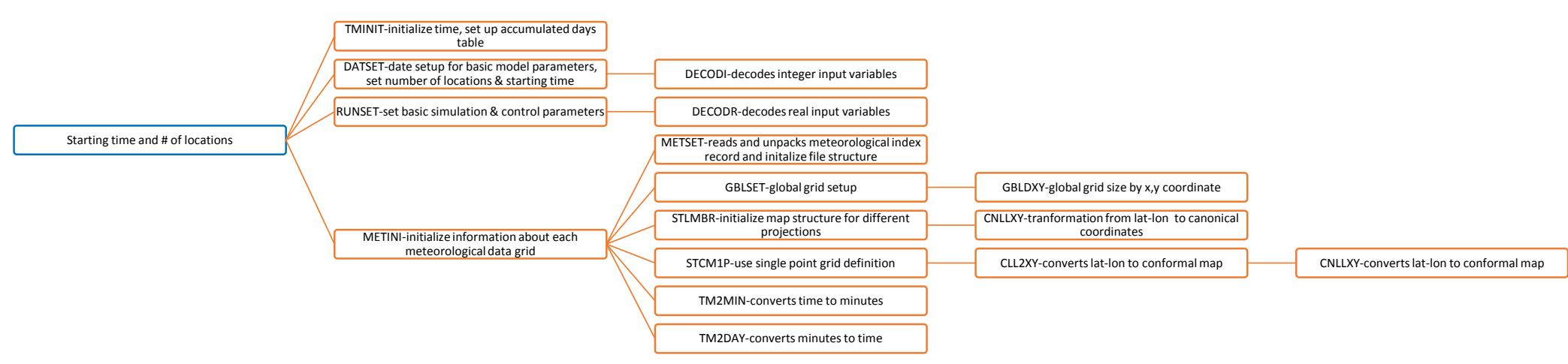

Define resolution of vertical meteorology grid METLVL-determines internal grid to interpolate meteorology input data
levels to internal levels, initialize time, set up accumulated days table

Convert starting time to accumulated minutes

TM2MIN-converts time to minutes

Starting position initialization

GBL2XY-converts lat-Ion position to $x$-y grid

CLL2XY-converts lat-lon to conformal map CNLLXY-converts lat-lon to conformal map

Starting time initialization

TMPLUS-converts a date plus hours to new date

Initialize trajectory endpoints output file

TRJSET-trajectory output setup 
APPENDIX B (continued)

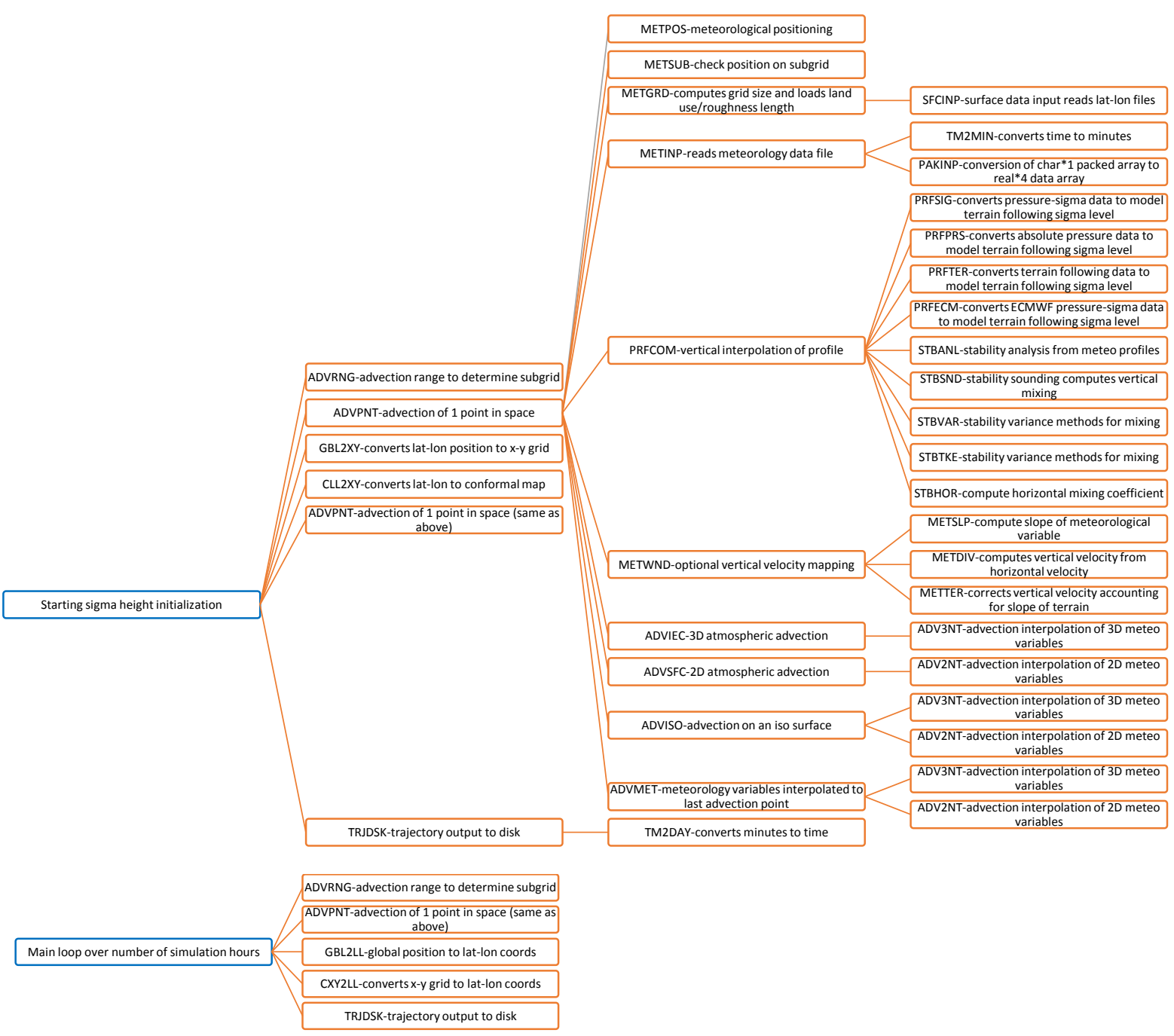

